
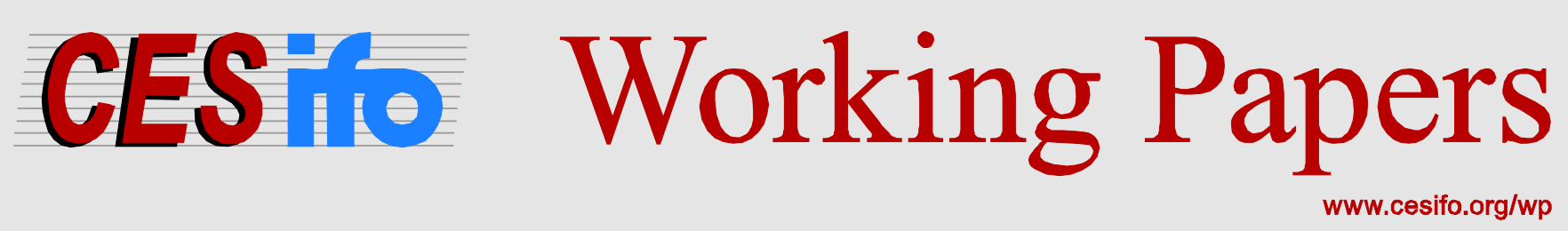

\title{
Competition and Innovation in Automobile Markets
}

\author{
Vivek Ghosal \\ Jiayao Ni
}

CESIFO WORKING PAPER NO. 5504

CATEGORY 11: INDUSTRIAL ORGANISATION

SEPTEMBER 2015

An electronic version of the paper may be downloaded

- from the SSRN website:

- from the RePEc website:

- from the CESifo website: wWw.SSRN.com

Www.RePEc.org

www.CESifo-group.org/wp 


\title{
Competition and Innovation in Automobile Markets
}

\begin{abstract}
Using data from the U.S. automobile market, we empirically examine the link between competition and innovation. Consistent with a large literature, we use patent counts as a measure of innovation. The combination of the U.S. market's economic importance, market dynamics, and the significant intertemporal fluctuations in firms' market shares and patents make this an interesting market to examine the link between competition and innovation. We use firm-level time-series data over a long horizon (1969-2012) for nine well established firms selling in the U.S. market (GM, Ford, Chrysler, Toyota, Honda, Nissan, Volkswagen, BMW, and Daimler). Some of our key findings are: (1) increase in firms' market shares result in higher patenting, and the relationship is reasonably non-linear; (2) higher market-wide competition results in an increase in patenting, and the relationship is weakly non-linear; (3) the (absolute) quantitative impact on patents is larger for firms' market share effect as compared to market-wide competition; (4) there is relatively strong path-dependence in firms' patenting behavior; and (5) we find interesting results linking patents to GM's bankruptcy, the Daimler-Chrysler merger, environmental regulations, voluntary export restraints, and firms' patenting over business cycles.
\end{abstract}

JEL-Code: L130, L620, O310, D210, M210.

Keywords: patents, innovation, market share, competition, automobiles, business cycles, mergers, environmental regulations, antitrust.

\author{
Vivek Ghosal* \\ School of Economics \\ Georgia Institute of Technology \\ Atlanta / Georgia / USA \\ vivekghosal@gatech.edu
}

\author{
Jiayao $\mathrm{Ni}$ \\ School of Economics \\ Georgia Institute of Technology \\ Atlanta / Georgia / USA \\ jni30@gatech.edu
}

*corresponding author

August 24, 2015

We thank participants at University of Tokyo (Tokyo, 2015), Düsseldorf Institute for Competition Economics (Düsseldorf, 2015), Centre for European Economic Research (Mannheim, 2015), Industry Studies Conference (Kansas City, 2015), CESifo Workshop on Applied Microeconomics (Munich, 2015), Ph.D. Innovation Economics class at Georgia Institute of Technology (2015), Shanghai Jiao Tong University (Shanghai, 2014), and the Southern Economics Association meetings (2014) for helpful comments. 


\section{Introduction}

Innovation is viewed as critical to fostering the growth of markets, generating efficiencies, and improving welfare. The degree of competition among firms has been recognized as one of the important factors influencing innovation. However, as we discuss in section 2, neither the theoretical nor the empirical literature provide clear evidence on the sign or the magnitude of this relationship. Studying the relationship between the competition and innovation is important for several reasons. If innovation generates growth of markets and efficiency, then creating institutions and markets that foster innovation are vital to increasing welfare. Further, if relatively more competitive markets generate greater innovation, then antitrust and regulatory policies, for example, would need to be structured and enforced appropriately to facilitate competition. ${ }^{3}$

In this paper we examine the relationship between competition and innovation in the U.S. automobile market, which, over our sample period, has perhaps been the most vibrant market with most of the major global producers competing to showcase their technological prowess and vying for market share. Focusing on the U.S. automobile market to examine the relationship between competition and innovation is meaningful for several reasons. First, the U.S. automobile market is economically large. Till the year 2010, the U.S. was the \#1 automobile market, before China overtook it starting 2011. Further, during the period 2004-2008, for example, the motor vehicles industry created about 1.1 million jobs in the U.S. This number is, for example, significantly greater than for semiconductors (0.48 million), aerospace (0.47 million) and pharmaceuticals (0.29 million). A recent report notes that the overall automobile industry is the largest in all of U.S. manufacturing sector, and generates large capital investments. ${ }^{4}$ Second, the U.S. market has seen dramatic intertemporal changes in the market shares of the main firms as well as patenting profiles. Around 1970, GM and Ford had a combined share of about 65\% of the U.S. market. By 2010, this sum had been reduced to about 30\%. The American firms' dominance was in part due to the home-market advantages, as well as important innovations that were introduced by them. ${ }^{5}$ The U.S. firms' leading

\footnotetext{
${ }^{3}$ As Cohen and Levin (1989, p.1060) note: "Schumpeter's propositions appeared to offer a direct challenge to the antitrust orthodoxy ... the proposition that an industrial organization of large monopolistic firms might have decisive welfare advantages cut sharply against the grain of antitrust thinking." They go on to write that: "Schumpeter's assertions inspired what has become the second largest body of empirical literature in the field of industrial organization, exceeded in volume only by the literature investigating the relationship between concentration and profitability." Gilbert (2006) provides a lucid discussion of antitrust and policy issues.

${ }^{4}$ American Automotive Policy Council (2014): "State of the U.S. Automotive Industry: Investment, Innovation, Jobs, and America's Economic Competitiveness.”

${ }^{5}$ For example, GM introduced important innovations over the years, such as the air bag, and the catalytic converter it created during the 1970s. Ford also introduced major innovations, such as large-scale manufacturing in 1914.
} 
positions were challenged by the Japanese firms in the aftermath of introduction of U.S. environmental regulations in the early-1970s, and the dramatic oil price shocks starting in 1973. While Toyota is the largest Japanese firm in the U.S. market by market share, Honda and Nissan are well established and offer significant competition to their rivals. Volkswagen, BMW, and Daimler are the three major manufacturers from Germany. VW competes with the U.S. and Japanese firms in the mass-produced segment, but its market share on average has been rather low. BMW and Daimler sell cars exclusively in the luxury segment, and are not directly comparable to the U.S. firms. However, they compete with Toyota, Honda, and Nissan in the luxury segments, as well as GM's Cadillac lineup to some extent. ${ }^{6}$

We use patents as an indicator of innovative activity. Patents are awards to firms' research, are visible outcomes of innovative activities, likely to be linked to new technologies introduced to the market, and relate to competition in technologies, market performance, and other aspects of firms' strategies. Apart from patents being a widely used measure of overall innovative activity, our choice of patents is motivated by the fact that we are able to compile a consistent database of patents by the automobile firms for the full sample period 1969-2012. Data on R\&D expenditures, an alternative indicator of innovation, were not available for the majority of the firms for most years in our sample period. Lacking consistent data in $\mathrm{R} \& \mathrm{D}$, we use patent counts to measure innovation. ${ }^{7}$ Our data show stark differences in both the mean level, and intertemporal variation, in the firms' patents.

The automobile industry shows healthy overall patenting, as well as product and process innovations. According to a USPTO report, the total patent count of the motor vehicles and related industry was $8,298 .^{8}$ This compares favorably to other industries such as medical equipment and supplies $(9,716)$, plastics and rubber products $(8,289)$, and is higher than in, for example, aerospace products and parts $(2,726)$, and fabricated metal products $(5,495)$. The motor vehicles patent count was lower than in industries such as basic chemicals $(12,109)$, and pharmaceuticals $(13,627)$. The USPTO report also presents information on the percent of product and process innovations for which

\footnotetext{
${ }^{6}$ One of the important reasons why we focus on the U.S. market is the availability of complete data on the major competitors. For the non-U.S. markets, we were unable to obtain complete data on market shares and other attributes over our time period. Overall, the data limitations for the foreign markets were rather severe. We note that ours is not the only study focusing on the U.S. market. The papers by Lieberman et al. (1990), Lieberman and Demeester (1999) and Lieberman and Dhawan (2005), for example, focus on the U.S. market.

${ }^{7}$ Though alternative measures have been used to indicate levels of innovation, patent data are a valuable source of firms' innovative activities and signal technological development over time and indicate potential future advances. Among the different patent statistics, total number of patents is a good indicator of overall innovative activities and has been used in numerous empirical studies (e.g., Scherer, 1965; Blundell et al, 1999; Aghion et al., 2005; Cockburn and MacGarvie, 2009; Hu, 2010; Lee et al., 2011; Hashmi, 2013; von Graevenitz et al., 2013). ${ }^{8}$ Economics and Statistics Administration and United States Patent and Trademark Office (2012): "Intellectual Property and the U.S. Economy: Industries in Focus.” The comparative industry data are for the period 2004-2008.
} 
patents were considered an effective mechanism for appropriating the returns to innovation. For the motor vehicles and related industry, 38.9\% of the managers considered patents as an effective protection of product innovations and $21.7 \%$ for process innovation. For comparison, the respective percentages for some other industries were as follows: aerospace (32.9\% and 21.4\%); computers (41\% and 30\%); machine tools (36\% and 18\%); and pharmaceuticals (50.2\% and 36.2\%). The motor vehicles percentages were higher than in, for example, electronic components (26.7\% and $15.2 \%)$ and semiconductors (21.3\% and 23.3). So whether we examine overall patenting rates or product and process innovation aspects, the motor vehicles industry appears to be quite vibrant relative to many other industries which have high overall rates of innovation and patenting.

A salient aspect of our study is that we use firm-level time-series data on measures of competition and innovation over a relatively long period (1969-2012) which enables us to better estimate the dynamic relationships in the market. We use dynamic panel data models to estimate the impact of firms' market shares and the market HHI on firms' patenting. Our panel models control for a range of factors related to GM’s bankruptcy, the Daimler-Chrysler merger, environmental regulations, voluntary export restraints, business cycle conditions, among others. To examine the above relationships, we focus on nine well established firms selling in the U.S.: GM, Ford, Chrysler, Toyota, Honda, Nissan, BMW, Daimler, and Volkswagen. While there are several other smaller firms in the market, our choice of nine firms is motivated by two reasons. First, these nine firms have, on average, accounted for approximately $91 \%$ of the sales in the market over our sample period. Second, data for these firms are consistently available over our entire sample period.

The paper is organized as follows. In section 2 we briefly review the theoretical results and empirical findings. In section 3 we develop our empirical specifications, and describe the data in section 4 . The estimation results are presented in section 5 . Conclusions and implications of our findings are noted in section 6.

\section{Review of the Literature}

The literature examining the linkage between competition and innovation is quite extensive and it is not our objective here to present a comprehensive overview. Some papers in the literature already do this, such as Cohen and Levin (1989), Ahn (2002), and Gilbert (2006). In this section we review some of the key theoretical results and empirical findings to focus on our empirical analysis. 


\subsection{Theoretical Results}

The early foundations of the literature relating competition to innovation were provided by Schumpeter (1934, 1942) and Arrow (1962). Schumpeter (1934) argued that the prospect of achieving monopoly rent induces a firm to invest in R\&D. Schumpeter (1942) noted that once a firm achieves a monopoly position through innovation, it will have an incentive to incur additional innovation expenditures to reinforce this position. A large firm is induced to seek innovation to increase and strengthen its market power. Arrow (1962) considered an inventor's decision in a competitive market versus a monopoly, and showed that pre-invention monopoly power acted as a disincentive for further innovation. Arrow’s prediction, in contrast to Schumpeter, was that firms with low market share - in an atomistic competitive market - would generate more innovations.

The market we study, automobiles, is best characterized as an oligopoly. While the above contributions established the bookends on the linkage between competition and innovation, the subsequent literature which used oligopoly models to attempt to resolve the contradictory results produced even more dispersion of results. An important reason is that the oligopoly models vary significantly in their structure and assumptions, such as those related to: mode of competition, Cournot versus Bertrand; whether the payoffs from invention are certain or uncertain; whether the input into patents - R\&D - is best described as only containing fixed costs, or a combination of fixed and variable costs; whether the innovation is drastic versus non-drastic (incremental); whether innovation game is played as a preemption or precommitment game; whether the game being modeled is a one-shot or a two-stage game; whether the timing of arrival of the technological opportunities is deterministic or stochastic; efficiency of firms' innovation projects; among others.

To illustrate the diversity of results from the oligopoly models, we briefly describe a few papers below, and in table 1 we present a summary of some of the theoretical results. ${ }^{9}$ Loury (1979) - assuming Cournot competition, fixed and no variable R\&D project costs, and uncertain date for project completion - found that as the number of firms increases (decrease in firm's market share), the incentive to invest in R\&D decreases. Lee and Wilde (1980) modified Loury’s model by assuming that innovation investments involve both an up-front fixed cost, as well as variable costs over the duration of the project. They showed that an increase in the number of firms increases firms'

\footnotetext{
9 There are other papers that shed light on firms' innovation activities which we do not address below as they are somewhat tangential to the focus of our study. For example, in Dasgupta and Stiglitz (1980), R\&D expenditures are positively related to market concentration. Their model, however, is about industry equilibrium with cross-industry implications, and less of within-industry results. Further, there is an emerging literature on patent thickets (e.g., von Gravenitz et al., 2013; Hall et al., 2012; Cockburn and MacGarvie, 2009). However, the specific issues examined in the patent thickets papers are somewhat different from our focus on the effects of competition on innovation.
} 
R\&D investments, a result exactly the opposite of Loury. Delbono and Denicolo (1991) noted that Lee and Wilde's results depend on the specific structure of the model related to incentives and payoffs - e.g., the innovation prize is exogenous and independent of the number of firms, and that no account is taken of the possibility that firms can have positive profits before the innovation. Delbono and Denicolo relaxed these assumptions and found that an increase in the number of firms may result in a decrease in firms’ R\&D investments - a result similar to Loury.

There are several papers that examine patenting strategies when firms face complex tradeoffs between expropriability of innovation and the degree of competition. Anton and Yao (2004), assuming Cournot competition, examine the tradeoff between the efficiency-enhancing aspect of patents and the likelihood of imitation. In their model, only a small innovation with an insignificant reduction in cost will be patented while a large one with a significant reduction in cost will not be patented. However, Mosel (2011), assuming Bertrand competition and a cost of applying for patents, generates the opposite result: only large innovations whose benefits of patenting outweigh the application costs will be filed for patents. Jansen (2011) examines patenting incentives in a model of asymmetric information, and focuses on the size of an innovation. He finds that under Cournot (Bertrand) competition, a firm will tend to patent large (small) innovations, and the incentive to patent grows (decreases) with an increase in the number of rivals. Overall, this literature shows that there is no general result. The precise magnitude and direction of patenting is heavily dependent on the complex interaction between the likely risk of expropriation and the mode of competition.

For our empirical analysis, we note two key aspects that emerge from the above studies: 1. The impact of competition on innovation is ambiguous. There is no clear prediction about the sign of the relationship. The answer depends on a wide range of factors noted above.

2. The models discussed above examine firms' total innovation efforts - total R\&D expenditures, or total patents. The theoretical models in this literature do not consider issues related composition of innovation (e.g., does greater competition generate more process or product innovation), or quality of innovation (e.g., does more competition generate low or high quality innovation). Given this, in our empirical study we focus on the effect of competition on the total innovation, as measured by the total number of patents generated by firms.

\subsection{Empirical Findings}

Given the wide range of results from the theory models, a significant empirical literature developed to shed light on the sign and magnitude of this important relationship. The empirical 
studies on the relationship between competition and innovation have produced no conclusive results. In table 2 we present a compact summary of some of the empirical studies, which show considerable diversity in the direction and characteristics of the relationship between competition and innovation. Below we, first, discuss some studies that have examined the relationship between industry-ormarket wide measures of competition and innovation. Second, we note some results relating to firmspecific market shares or performance to innovation.

The literature reviews by Cohen and Levin (1989) and Ahn (2002) noted that innovation and market concentration appear positively related in the majority of studies. However, the review by Gilbert (2006) shows no clear conclusions. Turning to specific papers, Acs and Audretsch (1988), Blundell et al. (1995, 1999), and Blind et al. (2006), for example, found a negative relationship between concentration and innovation. In contrast, Scherer (1965, 1967), Levin \& Reiss (1984), Scott (1984), and Levin et al. (1985) found little influence of concentration on innovation.

The empirical literature provides some evidence that the relationship between competition and innovation may be nonlinear. Scherer (1965) found a mildly nonlinear relationship between total number of patents and total sales. Blundell et al. (1995) also found nonlinearities: e.g., even though for the market as a whole there was a negative relationship between concentration and innovation, dominant firms were more likely to innovate. Aghion et al. (2001) and Aghion et al. (2005) predict a nonlinear, inverted U-shaped, relationship between competition and innovation. Using a mix of U.K. 2-digit industry data, and U.S. patents data, Aghion et al. (2005) reported evidence to support their model predictions. Hashmi (2013), however, finds exactly the opposite relationship. While Aghion et al. (2005) report an overall positive relationship between innovation and market competitiveness for the U.K. data, Hashmi finds a robust negative relationship. So even after addressing nonlinearities in the relationship, the results vary considerably across studies.

Turning to firm-specific factors, Blundell et al. (1995, 1999) and Lee et al. (2011), for example, found that innovation and market share were positively related. Scherer (1965) and Brouwer and Kleinknecht (1999) found that innovation and firms' sales were positively related. However, other studies found more intricate relationships: e.g., Hashmi and Biesebroeck (2006) find an inverted-U relationship between innovation and market share, and Noel and Schankerman (2013) find a dynamic intertemporal relationship between sales and innovation. Hu (2010) finds that patents increased not due to the expansion of firms' own sales, but by increase in competing imports.

The literature has examined several other factors that may affect firms’ patenting. For example, the influence of demand and technological opportunities (Cohen and Levin, 1989), and the influence of industry characteristics (Kondo, 1998). Focusing on issues related to appropriation and 
strategy, Cohen et al. (2002) suggest that Japanese and U.S. firms can be quite different, ${ }^{10}$ and Blind et al. (2006) use German data to study strategic patenting.

\subsection{Some Automobile Market Considerations}

In our review of the literature we noted the wide dispersion in findings relating firms' market shares, and degree of competitiveness, to firms' innovation and patenting. Several papers have emphasized the considerable inter-firm heterogeneity between the U.S. and Japanese automobile firms. For example, Lieberman et al. (1990) compared the productivity of six U.S. and Japanese automobile firms. Though the Japanese firms as a group showed an overall advantage in labor productivity over the U.S. firms, there was evidence of significant inter-firm divergence in productivity. Lieberman et al. argued that the primary cause for the disparity in productivity among those firms was inter-firm differences in management and strategy. Stressing firm-level impacts, Lieberman and Demeester (1999) analyzed the relationship between inventory and productivity in the Japanese automotive industry. Though for most firms the relationship turned out to be negative, the relationship was influenced by inter-firm differences especially for Toyota and Nissan. These two firms showed different patterns compared to other firms in the industry. Lieberman and Dhawan (2005) examined the differences in efficiency and performance among U.S. and Japanese firms, using the Resource-Based-View (RBV) approach. According to RBV, firms rely on unique and critical resources to maintain their competitive advantages. Lieberman and Dhawan found strong inter-firm variation in different facets of the firms' operations and performance. Finally, Lee et al. (2010, 2011) find important differences between U.S. and Japanese firms in patenting and other aspects. While these studies do not address the link between competition and innovation, they point to important heterogeneity across automobile firms in their underlying characteristics, as well as differences between firms grouped by their country of origin.

\subsection{Summary}

The broad research question is clear: What is the relationship between competition and innovation? However, neither the theoretical literature nor the empirical findings provide clear answers. The predictions relating market-share or market-concentration depend on the degree of

\footnotetext{
${ }^{10}$ First, firms use different appropriability mechanisms to protect innovations, among which patenting is treated as less effective than other methods in U.S., while more effective in Japan. Second, though strategic patenting is widely used in both U.S. and Japan, it is more prevalent in Japan. Third, Japanese firms are likely to use patents as substitutes in measuring market performance, a function that U.S. firms scarcely use.
} 
concentration and market structure, mode of competition - price or quantity, cost structure of innovation projects, nature of specific technologies being used, among other factors. In terms of the empirical literature, the evidence appears to indicate: ${ }^{11}$ (1) that market share tends to positively influence innovation; and (2) the impact of market-wide competition is far from clear.

We examine the sign, potential nonlinearities, and quantitative magnitudes in the relationship between firms' market shares and market-wide indicator of competitiveness (Herfindahl Index), and the automobile firms' innovation outputs as measured by patents. Our analysis provides evidence on broad, market-wide, effects, as well as shed light on heterogeneity of responses across firms. As the U.S. automobile market is economically large and shows substantial dynamics in both competition and innovation, it serves as an interesting setting to examine the broader research question.

\section{Empirical Specification}

Our objective is empirically examine the role played by firm-specific market share and market-wide competitiveness on the intertemporal dynamics of firms' patents. There is a substantial literature on estimation of dynamic specifications related to firms' decision variables, such as physical capital investments, R\&D investments, employment, and inventory holdings, among others. Eisner and Strotz (1963), Holt et al. (1960), Sargent (1978), Kennan (1979), Hendry et al. (1984), and Jorgenson (1986), for example, present expositions of the firms’ optimization theory behind these econometric models. ${ }^{12}$ Following this literature, we use a partial-adjustment framework to structure our empirical specification for patents. ${ }^{13}$ As Hendry et al. (p. 1045) note, partial adjustment models are one of the most common empirical specifications used to study dynamics. The partialadjustment model is based on a quadratic cost-minimizing framework where firms, when making their optimal adjustments related to the decision variable, aim to minimize disequilibrium and adjustment costs. The underlying models are framed in terms of a 'representative' firm, and then applied to data at various levels of aggregation.

The disequilibrium costs in these models arise due to lost profits from having the relevant decision variable at a sub-optimal level. For example, a delayed adjustment to the innovation path can lead to lost revenues and profits. Higher disequilibrium costs would, therefore, motivate a firm to adjust the innovation path faster. The adjustment costs are incurred when the firm attempts to align

\footnotetext{
${ }^{11}$ See the reviews by Cohen et al. (1989), Ahn (2002), Gilbert (2006), and our brief summaries in table 2.

${ }^{12}$ As the theoretical basis and econometric issues for these models have been widely discussed in these papers and the broader literature, we do not repeat the details here.

${ }^{13}$ Partial-adjustment models have been used for examining innovation dynamics: e.g., Falk (2006) and Lokshin and Mohnen (2012) for R\&D, and Kim et al., (2012) for patents.
} 
the actual quantity of the decision variable to its optimal level. A firm's attempt to more quickly alter its innovation path will result in higher adjustment costs. For example, rapid adjustment of the innovation path would require a faster adjustment of stocks of scientific personnel, capacity of research laboratories, reallocation of funds related to R\&D, processing and filing of patents, among other factors. Higher adjustment costs would, therefore, motivate a firm to adjust the innovation path more smoothly and slowly. The disequilibrium costs and adjustment costs, therefore, act in opposite directions. This implies that the actual speed of adjustment of the innovation path will be a weightedaverage of the two countervailing forces.

Denoting a firm's patents by PAT, the partial-adjustment model is given by (1).

(1) $\ln P A T_{t}-\ln P A T_{t-1}=\lambda\left(\ln P A T_{t}^{*}-\ln P A T_{t-1}\right)$.

In (1), $\ln$ denotes natural logarithms, t denotes time, $P A T_{t}^{*}$ is the optimal (or equilibrium) value of $P A T$ in period $\mathrm{t}$, and $\lambda$ is the speed-of-adjustment parameter. The actual intertemporal adjustment of patents $\left(\ln P A T_{t}-\ln P A T_{t-1}\right)$ is typically a fraction $\lambda(0 \leq \lambda \leq 1)$ of the desired intertemporal adjustment $\left(\ln P A T_{t}^{*}-\ln P A T_{t-1}\right)$. High (low) values of $\lambda$ imply high (low) speed-of-response. As the variables are measured in logarithms, the differences in the variables are interpreted as percentage changes and allow us to interpret the coefficients in the specifications (below) as elasticities.

We rewrite (1) as:

(2) $\ln P A T_{t}=(1-\lambda) \ln P A T_{t-1}+\lambda\left(\ln P A T_{t}^{*}\right)$.

In (2), $P A T_{t}^{*}$ is private information to the firm and not directly observed by the external researcher. We model $P A T_{t}^{*}$ as:

(3) $\ln P A T_{t}^{*}=\psi \ln Z_{t}$,

where $Z_{t}$ includes relevant driving variables, which we describe in detail in sections 3.1 and 3.2.

\subsection{Own Market Share, HHI, and Patents}

Our primary specification is a logarithmic-linear dynamic panel data model which examines the relationship between firms’ own market shares, market Herfindahl-Hirschman Index (HHI), and 
patenting activity. Returning to (3), $Z_{t}$ is modeled as a function of the firm's own market share, the $H H I$, and a set of other control variables:

(4) $\ln \left(Z_{t}\right)=\xi_{1} \ln \left(S H R_{t-1}^{i}\right)+\xi_{2} \ln \left(H H I_{t-1}\right)+\Psi X$,

where $\boldsymbol{X}$ is the vector of control variables discussed below. Using (4), (3) and (2), our panel data model is:

(5) $\ln \left(P A T_{t}^{i}\right)=\alpha^{i}+\tau_{1} \ln \left(P A T_{t-1}^{i}\right)+\tau_{2} \ln \left(S H R_{t-1}^{i}\right)$

$$
+\tau_{3} \ln \left(H H I_{t-1}\right)+\vartheta X+\epsilon_{t}^{i}
$$

In (5), $P A T_{t}^{i}$ is the annual total number of patents for firm $i, \alpha^{i}$ is the firm-specific intercept, $S H R_{t-1}^{i}$ is the lagged own-market share of the firm, $H H I_{t-1}$ is one lag of $H H I, X$ is a vector of other controls (discussed below), and $\epsilon_{t}^{i}$ is a firm-specific error term. ${ }^{14}$

We include both firm-level market share and HHI in our estimated specification. ${ }^{15}$ This is motivated by several factors. First, including market share allows us to examine how the market position of the firm itself affects patenting, and including HHI allows us to examine how marketwide competitiveness affects patenting. Including both allows us to examine the effect of one, controlling for the other. Second, the underlying theory models and the extant empirical literature often examine and find different effects of firm-specific market-shares and market-wide competitiveness. ${ }^{16}$ Third, our data (detailed in section 4) show dramatic reallocation of market shares across firms over our sample period, and the ensuing time-path of HHI. If our sample had only two firms, it would not be meaningful to include both market share and HHI. But with nine firms, and significant intertemporal market share and HHI dynamics, it is meaningful to control for both.

\footnotetext{
${ }^{14}$ Log-linear specifications are common in estimating patent specifications. We do not use negative Binomial models as our sample contains large well-established multinational firms with continuous and relatively high patenting profiles. Negative Binomial models are more appropriate when the sample contains small and startup firms with over-dispersion of patent counts (e.g., many zeros combined with large jumps in patents). Given the continuous nature of our patents data, we use a log-linear specification - which has been used in numerous earlier studies on patenting: e.g., Kondo (1999), Kortum and Lerner (1999, 2000), Hall and Ziedonis (2001), Hu (2010), and von Graevenitz et al. (2013).

${ }^{15}$ Previous studies have included a measure of firm-specific market share (or related variable) and an industry-wide competition measure: e.g., Blundell et al. $(1995,1999)$ and Scherer $(1965)$. An additional point we note is that in our panel, the correlation between firms' market share and HHI is 0.02 - so there is no obvious collinearity issue. ${ }^{16}$ E.g., Acs and Audretsch (1988), Blundell et al. (1995, 1999), Aghion et al. (2005), Hashmi and Biesebroeck (2006), Hu (2010), Hashmi (2013), and Noel and Schankerman (2013).
} 
The vector $\boldsymbol{X}$ includes the following control variables:

(a) The U.S. environmental and emissions control standards - Clean Air Act - that were introduced in the early 1970s with subsequent increases in standards in later years affected the patenting behavior of firms due to the need to generate newer products and processes to meet the emissions standards (Lee et al., 2010, 2011). They found that the environmental effect was most pronounced for the initial introduction of standards 1970-1973, with much smaller estimated effects during the 19901993 period, and that the effects were asymmetric across firms. There are important differences between the Lee et al. papers and ours. First, our focus is on competition and total patents. They study the link between emissions-control related patents and the regulatory standards. Second, our sample period is much longer. Nevertheless, we follow Lee et al. and control for potential policyinduced effects and create two dummy variables: Enviro1=1 if years equal 1969-1974, else Enviro1=0; and Enviro2=1 if years equal 1989-1994, else Enviro2=0. Each of our dummy variables covers a slightly wider period than Lee et al. (2011). ${ }^{17}$ As Enviro1 and Enviro2 are general effects, potentially affecting all firms, we include these as controls in all specification we estimate; (b) Daimler-Chrysler merger (Merger). This was an important event in this industry involving two large and prominent firms. In our data description (section 4) we provide details of our adjustments to the data to account for this merger.

(c) GM’s bankruptcy (Bankruptcy). Bankruptcy=1 if year 2009-2012, else Bankruptcy=0. The dummy variable covers GM’s bankruptcy period. Our prior is that financial stress and significant losses had the potential to negatively affect GM's innovation activities. Since the Bankruptcy dummy is specific to GM, we include this as an additional control for GM;

(d) Voluntary Export Restraints (VER). VER=1 if year equals 1981-1985, else VER=0. VERs were negotiated between the U.S. and Japanese Governments to restrict exports of automobiles from Japan to the U.S. for the specified period. While we are not aware of a study that directly links VER to patenting, our conjecture is that it had the potential to alter firms' incentives to innovate. As VER is a general effect potentially affecting all firms, we include this as a control in all specifications; and

\footnotetext{
${ }^{17}$ E.g., our period 1969-1974 instead of their 1970-1973; and our period 1989-1994 instead of their 1990-1993. Our justification for expanding the window for the environmental dummies is that the impending changes in policy were forecastable by the firms as the regulations went through extensive legislative discussions; hence an earlier start year of 1969. And some of the effects on innovation took more time to materialize; hence a slightly expanded terminal year for the dummy, 1974. Similarly for Enviro2 covering the period 1989-1994. The Corporate Average Fuel Economy (CAFE) standards also affected product development, engine design, among other changes. In terms of practical implications, while the standards for passenger cars went into effect earlier, the high fuel economy standard of 27.5MPG was effective starting 1990, with the next increase to 30.5MPG in 2011. The key item, the high standard of 27.5MPG, is roughly covered by our Enviro2 dummy (1989-1994), and overlaps with Lee et al. (2011) discussion of emissions standards.
} 
(e) Business cycles (GDP). We include GDP as there is an important literature that has examined the cyclicality of firms’ innovation activities, and effects of business cycles on R\&D and patenting. ${ }^{18}$

In addition to the above, our estimated specification (5) includes two important controls: (a) a firm-specific intercept $\alpha^{i}$; and (b) lagged firm-specific patents $P A T_{t-1}^{i}$. The fixed-effect $\alpha^{i}$ controls for unobserved firm-specific long-run differences in patenting across firms. This provides a control for some of the findings in the literature related to considerable variation in automobile firms' organizational structure, innovation and productivity strategies, and outcomes. ${ }^{19}$

The lagged-dependent variable $P A T_{t-1}^{i}$ is a critical control for the intertemporal dynamics of firms' patenting. It controls for at least two key aspects. First, it controls for any persistence in the intertemporal path of patents. If the dependent variable $P A T_{t}^{i}$ shows persistence, or path-dependence, and we omit $P A T_{t-1}^{i}$, the resulting slope coefficients in the estimated specification can be misleading. Second, $P A T_{t-1}^{i}$ serves as a control for an important omitted firm-specific time-varying factor that may influence the path of $P A T_{t}^{i}$ - firms’ R\&D expenditures. R\&D is a key control in patent production function specifications (e.g., Hall and Ziedonis 2001, Kortum and Lerner 2000, and the literature surveyed there). Unfortunately, we do not have data on the firms’ R\&D spending. Our attempts to obtain a consistent time-series for the nine firms in our sample were unsuccessful. The primary problem lies with obtaining R\&D data for the foreign firms, some of which are not publicly traded in the U.S. exchanges. Our full sample contains nine firms with time-series data for 44 years (1969-2012). Of the total 396 firm-years of observations, R\&D data were not available (from Compustat North America or Global, and other firm-level databases) for 158 firm-years. However, $P A T_{t-1}^{i}$ provides an indirect control for $\mathrm{R} \& \mathrm{D}$ in specification (5).

To examine R\&D expenditures, consider (6) which represents a baseline patent-production function model relating patents to R\&D (e.g., Hausman et al., 1984; Kortum and Lerner, 2000; Hall and Ziedonis, 2001):

(6) $P A T=\theta R \& D^{\beta}$

Converting (6) to log-linear form we get:

\footnotetext{
${ }^{18}$ E.g., Geroski and Walters (1995), Guellec and Ioannidis (1997), Barlevy (2007), Ouyang (2011), and Aghion et al. (2012).

${ }^{19}$ E.g., Lieberman et al. (1990), Lieberman and Demeester (1999), Lieberman and Dhawan (2005), and Lee et al. (2010, 2011).
} 


$$
\ln \left(P A T_{t}^{i}\right)=\ln \theta^{i}+\beta \ln \left(R \& D_{t}^{i}\right)
$$

In (7), $\theta^{i}$ is the firm-specific fixed-effect, and $R \& D_{t}^{i}$ is time-varying firm-specific R\&D expenditures. As discussed by Hall and Ziedonis (2001) and numerous other papers in this literature, using deeper lags of $R \& D$ provide no useful information beyond including the most current $R \& D$ data. Hall and Ziedonis (p.113) write:

"This literature largely concludes that the lag structure is very poorly identified because of the high within-firm correlation of $R \& D$ spending over time. When many lags are included in the model, the estimate of the sum of the coefficients is roughly the same as the estimated coefficient of contemporaneous $R \& D$ when no lags are included ... Experimentation with lag structures using these data confirmed the results in the earlier literature. For this reason ... we use contemporaneous levels of $R \& D$ spending in our specifications."

Given this, the basic specification (7) mimics the core relationship between R\&D and patents. Specification (7) lagged one period gives us (7'):

$\left(7^{\prime}\right) \ln \left(P A T_{t-1}^{i}\right)=\theta^{i}+\beta \ln \left(R \& D_{t-1}^{i}\right)$

Our specification (5) includes the lagged-dependent variable $P A T_{t-1}^{i}$. Substituting (7’) into (5) implies that the coefficient $\tau_{1}$ in specification (5) embeds the intertemporal dynamic effects of firms' $\mathrm{R} \& \mathrm{D}$ on patents, by accounting for the term $\beta \ln \left(R \& D_{t-1}^{i}\right)$ from (7’).

We note two additional points. First, any systematic steady-state differences across firms in their patenting profile is captured by the firm-specific fixed-effect $\alpha^{i}$. If there are steady-state differences in firms’ R\&D spending, and corresponding steady-state differences in their patenting, it would be controlled by $\alpha^{i}$. Second, specification (5) includes real GDP growth. Given that the literature indicates that innovation activities of firms and their R\&D has a cyclical component, the GDP growth terms control for these cyclical effects.

While due to lack of consistent and complete data we cannot include R\&D directly in specification (5), it incorporates important indirect controls for firms' R\&D expenditures by including $P A T_{t-1}^{i}, \alpha^{i}$ and GDP growth. 
Finally, we experimented with including deeper lags of SHR and HHI. First, the deeper lags of SHR are highly correlated in the data. ${ }^{20}$ The same problem exists with $H H I$. Including these lags produced a very high degree of collinearity between these deeper lags. Second, and more importantly, when we estimated specification (5) with the two lags entered separately, the second lag was typically insignificant, and did not have any meaningful contribution to explain movements in $P A T_{t}^{i}$. Given these, we do not include deeper lags in our estimated specifications.

We present two sets of dynamic panel data estimates for specification (5): (a) include all the nine firms. Given that our data cover the period 1969-2012, this gives us 396 firm-years of data in this panel; and (b) given that the literature points to interesting differences across firms grouped by countries, especially U.S. and Japanese, we re-estimate (5) by firms grouped by countries: U.S., Japan, and Germany. As each panel now has three firms, each country-group panel has 132 firmyears of data. We do not interact the variables in specification (5) by country dummies as this produced collinearity problems with the extensive set of included variables and then those variables interacted with the country dummies. ${ }^{21}$ Since this produces misleading inferences, we avoid this strategy. Using country-group sub-samples allows us to avoid these inference problems and directly examine the differences in the full range of estimated slope coefficients. In section 5 we provide details about our estimation methods.

\subsection{Own Market Shares, Rivals’ Market Shares, and Patents}

In this section, we ask a slightly different question. In considering its patenting (innovation) response, does the firm care about the market shares of specific rivals? For example, does GM care more about the market shares of its U.S. competitors or Japanese? Examining this might provide additional insights into the complex interaction between competition and patenting.

To examine this, we drop HHI from specification (5) and replace it with the market shares of rivals segmented into three broad categories (we do not include market shares of each rival in the estimated model as this would result in a proliferation of parameters to be estimated):

(a) Own-Country rivals' total market share. For example, for GM this variable would be the sum of the market shares of Ford and Chrysler. For Honda, this would be the sum of the market shares of Toyota and Nissan;

\footnotetext{
${ }^{20}$ For example, the overall correlation between $S H R_{t-1}^{i}$ and $S H R_{t-2}^{i}$ for the nine firms in our sample is about 0.95 . Examining the firm's individually, the correlations are: GM (0.975), Ford (0.946), Chrysler (0.835), Toyota (0.983), Honda (0.988), Nissan (0.947), VW (0.918), BMW (0.985), and Daimler (0.982).

${ }^{21}$ For parsimony, each included variable in specification (5) would have to be interacted with a country dummy.
} 
(b) Other-Country:Main rivals' total market share. This segment constitutes the primary or 'main' foreign rivals. Here, we consider the U.S. (Japanese) firms' other-country 'main' rivals as the Japanese (U.S.) firms. ${ }^{22}$ For the German firms, we consider the Japanese firms as their other-country 'main' rivals due to the Japanese firms' luxury segments competing with the German firms. For example, for GM this variable would be the sum of the market shares of Toyota, Honda, and Nissan. For Honda, this would be the sum of the market shares of GM, Ford, and Chrysler; and

(c) Other-Country:Other rivals' total market share. This segment constitutes the secondary or 'other' foreign rivals. For the U.S. (Japanese) firms this 'other' category would be the German firms. For the German firms, the other category would be the U.S. firms. For example, for GM this variable would be the sum of the market shares of Volkswagen, BMW, and Daimler. And the same for Honda.

Disaggregating the foreign rivals into the 'main' (primary) and 'other' (secondary) is meaningful given the market characteristics of these firms. For example, for the U.S. firms, the Japanese are clearly the main rivals due to the significant overlap in the mass-produced segments. ${ }^{23}$ The segmentation of rivals by countries is also broadly consistent with some of the findings on important differences between, for example, U.S. and Japanese firms. ${ }^{24}$

The estimated specification is:

$$
\begin{aligned}
\ln \left(P A T_{t}^{i}\right)=\kappa^{i}+\gamma_{1} & \ln \left(P A T_{t-1}^{i}\right)+\gamma_{2} \ln \left(S H R_{t-1}^{i}\right) \\
+\gamma_{3} & \ln \left(S H R_{t-1}^{\text {Own-Country }}\right)+\gamma_{4} \ln \left(S H R_{t-1}^{\text {Other-Country:Main }}\right) \\
& +\gamma_{5} \ln \left(S H R_{t-1}^{\text {Other-Country:Other }}\right)+\xi \boldsymbol{X}+\omega_{t}^{i} .
\end{aligned}
$$

As we discussed for specification (5), $\boldsymbol{X}$ is the vector of other control variables. As we noted for specification (5), we present two sets of panel estimates for specification (8): (a) include all the nine firms; and (b) estimate the panel models with data for firms grouped by countries. As discussed earlier, we do not pursue the strategy of interacting the model variables with country dummies due to the proliferation of interaction terms and dummy variables. By estimating country-group sub-

\footnotetext{
${ }^{22}$ Considering the Japanese (U.S.) firms as being the main foreign rivals of the U.S. (Japanese) firms in the U.S. market appears reasonable. First, the overall market shares of the German firms is very low, in part because BMW and Daimler are competing in a somewhat different market segment, and in part due to VW's market share remaining low. Second, in terms of intertemporal dynamics, the Japanese firms show the most significant gains.

${ }^{23}$ As we note in section 4, while Volkswagen is a mass-market competitor, on average it only has about a $2.5 \%$ market share in the U.S. over our sample period. In several of the years in our sample, BMW actually sold more cars in the U.S. than VW. In this sense VW is not viewed as a primary competitor for the U.S. firms.

${ }^{24}$ E.g., Lieberman et al. (1990), Lieberman and Demeester (1999) and Lieberman and Dhawan (2005).
} 
samples, we allow the full set of slope parameters to vary across the estimated models. In section 5 we provide details about our estimation methods.

\section{Data Description}

In our analysis of the impact of competition on patenting in the U.S. automobile market, we examine data over a 44-year period, $1969-2012 .{ }^{25}$ We examine data on nine firms: GM, Ford, Chrysler, Toyota, Honda, Nissan, Volkswagen, BMW, and Daimler. This set covers the big-three U.S., Japanese, and German firms. While we considered including some of the other firms selling in the U.S. market, our reasons for restricting it to the nine prominent firms were as follows. First, some of the data we use were consistently available only for these nine firms. For several of the other firms we considered, there were gaps in the data on market shares and sales. ${ }^{26}$ Second, the main new entrants in the U.S. market, Hyundai and Kia, were meaningful players only towards the end of our sample period, and their data were incomplete or missing for many of the earlier periods. Third, over our sample period (1969-2012), the nine firms on average accounted for approximately $91 \%$ of the sales in the U.S. market, therefore accounting for the vast majority of sales. Given this, we restricted our sample to the nine firms to allow us to do a thorough analysis with complete data on each firm.

It could be argued that BMW and Daimler are luxury brands, and therefore not directly comparable to the other firms. The counter arguments are that Toyota, Nissan, and Honda all have their distinct luxury divisions - Lexus, Infinity and Acura. While the luxury segment is relatively weak for the U.S. firms, Cadillac, for example, is GM's luxury segment. In addition, we note that Toyota's patents, for example, are reported under Toyota Motor Co. and not separately under Toyota and Lexus. So, for the mass market firms, there is no way to segment their patents into the mass produced versus luxury divisions. Moreover, Japanese firms, for example, often use the same platform design, engines, among other components, across their mass-produced and luxury lineups. ${ }^{27}$

\footnotetext{
${ }^{25}$ We use 1969 as the start year as that was the first year we could get consistent market share data on all the firms in our sample. The starting date is also important as the late-1960s and early 1970s were important in this industry due to the introduction of emissions and other regulatory controls, as well as the oil price shocks starting 1973. And 2012 was the most recent year for which data were available when we started this project.

${ }^{26}$ For example, Hyundai and Kia are relatively recent successes. The Wards Automotive data - which contains the most comprehensive data for sales in the U.S. automobile market - shows no recorded sales of Hyundai till 1986. Starting 1986 it shows very small sales of Hyundai Excel. Kia shows no recorded sales till 1993, when it shows Kia Sephia with 692 cars sold. To accommodate Hyundai and Kia we would have to start our sample around early1990s, losing valuable observations on the historical dynamics in this market. Similarly, if we look at Subaru, our sample period average market share is about $0.8 \%$ along with missing data for several of the initial years. If we include such firms we would lose a large number of observations with no clear econometric or conceptual benefit. ${ }^{27}$ E.g., the Lexus ES 350 is the best-selling model for Toyota/Lexus. Edmunds (www.edmunds.com) notes: "The current-generation Lexus ES ... shares its platform architecture and overall footprint with the Toyota Avalon full-
} 
Given these considerations, we decided to keep BMW and Daimler in our broader sample to offer some comparisons. In our estimation, we present panel data estimates using all nine firms, as well as by grouping firms by countries, allowing us to look at results with and without the German firms.

\subsection{Patents}

For the period 1969-2012, we collected data on patents for the nine firms from the U.S. Patent Office (USPTO). We use successful (granted) patent applications for our analysis. To obtain the total number of patents for each firm, we had to address a couple of important issues related to Ford Motors, and the Daimler-Chrysler merger.

For Ford Motors, the total patents assigned appear under: (i) Ford Motor Co.; and (ii) their technology subsidiary Ford Global Technologies. After 1997, the vast majority of patents for Ford are assigned to this technology subsidiary. Given this, we add the patents for Ford Motor Co. and Ford Global Technologies to obtain the total patents for Ford. This creates a consistent time series for all patents for Ford Motors.

The merger between Chrysler and Daimler was an important event. They merged on (November 12) 1998 and broke up on (May 14) 2007. The merger resulted in the total number of patents for both companies dropping to zero as all new patents were assigned to the new entity 'DaimlerChrysler.' Chrysler and Daimler began to have their own patents assigned again after the break up in 2007. To address this issue, one option for us was to drop both Chrysler and Daimler from the sample. But this is not desirable as it would result in omission of two large and important firms from the sample. Another option was to include a merger dummy to cover the roughly 9 year merger period. But this is also not very useful as the lack of time-series data over this extended merger period would reduce our ability to understand the intertemporal dynamics of competition and patenting. Instead, we use the approach noted below to create a merger-adjusted patents time-series for Chrysler and Daimler.

\footnotetext{
size sedan.” Regarding the Lexus CT 200h, Edmunds writes: “The Lexus CT 200h’s high fuel economy is due to its hybrid powertrain .... Fitted with essentially the same system that Toyota uses for the Prius." Acura is Honda's luxury division. Both Car and Driver (http://www.caranddriver.com) and Edmunds note that the "Acura ILX is basically a Honda Civic." While the refinements and passenger comfort items vary, a deeper reading of the automotive reviews at Edmunds, Car and Driver, Motor Trend, among others, reveals information on how several of the automobile firms share platforms, engines, and overall architecture across their mass-produced and luxury models. The objective is obviously to reap greater economies of scale and scope in their expenditures related to $\mathrm{R} \& \mathrm{D}$, design, and overall product development.
} 
First, over the 10 -year period $1989-1998,{ }^{28}$ we compute the total number of patents for Chrysler and Daimler: PAT ${ }^{\text {Chry+Daim }}$. Next we calculate the fraction of total patents accounted for by each company during this 10-year pre-merger period: $\left(P A T^{\text {Chry }}\right) /\left(P^{\text {A }} T^{\text {Chry+Daim }}\right)$ and $\left(P A T^{\text {Daim }}\right) /\left(P A T^{\text {Chry+Daim }}\right)$. These two ratios 'roughly' indicate the individual firms' patent shares in the pre-merger period, if the two firms were actually combined. Our data indicate that while there is a small amount of variation in these two fractions, they appear relatively stable over the 10-year pre-merger period. To smooth out shorter-run, year-to-year, variations in this ratio, we use the average fraction from the 10-year pre-merger period. The values of these pre-merger ratios are: $\left(P A T^{\text {Chry }}\right) /\left(P A T^{\text {Chry+Daim }}\right)=0.45$, and $\left(P A T^{\text {Daim }}\right) /\left(P A T^{\text {Chry+Daim }}\right)=0.55$. Next, we assume that over the actual merged period, the true share of patents accruing to Chrysler remains at 0.45 . Using this, we assign 0.45 of the merged DaimlerChrysler entity's total patents to Chrysler, and the remaining 0.55 to Daimler. Using this procedure, we create a merger-adjusted continuous time-series in the patents granted to Chrysler and Daimler over the period they were merged.

After the merger broke up in 2007, some patents continued to be granted to the combined DaimlerChrysler entity during 2008-2010 due to the administrative and legal processes. For the period 2008-2010, we use the same procedure as noted above to separate the patents assigned to DaimlerChrysler and allocate those to Chrysler and Daimler.

In combination, our above procedure gives us a merger-adjusted time-series in patents for Chrysler and Daimler for the full sample period, 1969-2012. Apart from the 1989-1998 based calculations noted above, we experimented with a five year period 1994-1998, as well as redoing the calculations by leaving out the year 1998. The merger-adjusted time-series we create are not sensitive to the exact pre-merger years we consider to do our calculations.

Even after making the above adjustments to create a continuous time-series for patents for Chrysler and Daimler, there is a discrete jump in patenting for both firms around the period 19982002. This is not the entire merger period 1998-2007, but a sub-period. Before 1998 and after 2003, each firm's series looks in conformity with their longer-run patterns. There appears to be some merger-related complexities over the period 1998-2002 that are not being fully captured by our adjustment. While the exact analysis and effects of the merger on the firms' innovation is beyond the scope of this paper, we control for this phenomenon by including a merger dummy (Merger):

\footnotetext{
${ }^{28}$ We treat this as the pre-merger period in our calculations below. While the merger was consummated on (November 12) 1998, DaimlerChrysler began to have patents assigned to this merged entity starting 1999. Therefore, using 1998 as the terminal year to do our calculations does not affect our analysis. As we note later, altering the time periods to do our calculations does not affect any of our conclusions.
} 
Merger=1 if year 1998-2002, else Merger=0. Since the Merger dummy is specific to Chrysler and Daimler, we include this as an additional control for those two firms only. ${ }^{29}$

Table 3 presents the summary statistics for the patents data. The sample average number of patents for GM, Ford, Toyota, and Honda are relatively close at 333, 260, 277, and 351, respectively. Chrysler has the lowest patent profile of the three U.S. firms, and Nissan the lowest among the Japanese firms. Daimler, the most active German firm, has a sample mean of 111 patents, which is almost four times larger than VW or BMW. The sample averages conceal important underlying dynamics. Two Japanese firms, Toyota and Honda, have aggressive patenting profiles during the latter half of the sample period during which they surpass the peaks of GM. The German firms individually, or as country total, have relatively stable profiles.

Figure 1 plots the firms' USPTO patents - grouped as country totals. Overall, the U.S. total shows relative stability. The two big deviations in the U.S. totals come around 1970-1974 (mainly due to sharp increase in GM’s patents, potentially related to the Clean Air Act) and 2008-2010 (entirely due to drop in GM’s patents during its bankruptcy period). In contrast, the Japanese patents show sharp acceleration towards the end of our sample period. This is almost entirely driven by spikes in patenting by Toyota and Honda. ${ }^{30}$ The German profile is one of relative low and stable patenting. The increase in the German profile around 1999 to 2002 is entirely due to an increase in Daimler's patents during that period (related to the merger with Chrysler).

An intriguing feature is the three German firms' low total patent counts compared to the U.S. or Japanese firms. Daimler, the most active firm of the three German companies, has a peak of 250 patents in 2000, which is still much lower than the averages of GM and Ford, and even lower than the average of the Japanese firms in 1985. For VW and BMW, their total numbers of patents are consistently low. This is puzzling given the reputation of the German firms' innovative capabilities.

It is clearly the case that the U.S. market is very important to the German automobile firms. Over our sample period, BMW has sold roughly 23\%-28\% of its global production in the U.S. market. A similar significance holds for Daimler. In terms of profits, a similar fact holds where the high-demand and high-income U.S. market has been historically important for BMW and Daimler. Given this, one would expect the German firms to have a healthy patenting profile in this important

\footnotetext{
${ }^{29}$ We do not consider other mergers during our sample period, such as those of Volvo (by Ford) and Saab (by GM), as these were very small firms. Our examination of these mergers revealed very little impact on the acquiring firms.

30 The sharp increase in Toyota's patents during the end of our sample period are largely due to increase in their patents related to automotive fuel-cell related technologies: http://fortune.com/2015/01/07/toyota-fuel-cell-patents/ . To a considerable extent, this is also true of Honda and their fuel-cell technologies.
} 
market, much like the Japanese. While the lower patenting profile of the German firms is rather curious, we were unable to find explanation of this in the literature in spite of extensive searching.

To examine if our USPTO automotive patents data on the German firms were an aberration, we examined data from the OECD database containing country-total triadic patents. Note that these are not just automotive patents, but all patents from each country. Figure 2 plots the country-total triadic patents. It is clear that Germany's country total triadic patents are an order of magnitude lower than either U.S. or Japan. Figure 2 shows that the U.S. and Japanese county total triadic patents are relatively similar, and about four times larger than the German total. Setting aside specific differences, our USPTO-based auto patents (displayed in Figure 1) are not an aberration. German patents appear to be systematically lower.

We end this section with a comment linking the observations from the data to our econometric estimation. Our patents specification (5) - see section 3 - includes a firm-specific fixedeffect $\alpha^{i}$ which controls for the long-run steady-state differences in firms' mean levels of patents noted in the summary statistics presented in Table 3. Whatever firm-specific reason exists to generate different levels across the firms, $\alpha^{i}$ controls for it. What is important for estimation of the slope coefficients is whether there are intertemporal fluctuations in patents. Examining table 3, we see that the coefficient of variation is quite high for all firms in the sample. Even though the German firms have lower levels of patenting compared to their U.S. and Japanese counterparts, the coefficient of variation of the German firms’ patents are comparable to the other firms.

\subsection{Market Share}

Data on sales in the U.S. and market shares are from Ward's Automotive. Ward's offers the most comprehensive and historical data on U.S. market sales. According to the data on total light vehicles sales from Ward's Auto, the nine firms in our sample dominate the automobile industry with an average market share of 91\% over the sample period 1969 to 2012. Table 4 presents the summary statistics on market shares. The sample averages show that the U.S. firms have the highest market shares, and the German firms with the lowest shares. While the low shares of BMW and Daimler are understandable as they operate in the luxury segment, the low market share of Volkswagen, a mass market firm, reveals significant failure to compete with either the U.S. or the Japanese firms. ${ }^{31}$

\footnotetext{
${ }^{31}$ VW's historic problems are also current ones. As noted in Forbes (07/03/2014): “Volkswagen has been and continues to be in a new product drought. It simply doesn't have the vehicles or the breadth of product portfolio to capitalize...” Wall Street 24/7 (05/02/2015) notes: “The two primary arguments about VW's failure in America are that its model line is too limited and the amount of successful competition is too great. The problems converge."
} 
As with the patents data, the sample average for the market shares conceals important underlying dynamics. Figure 3 displays the market share by country averages. The three U.S. firms combined started with a high market share of around $80 \%$ in 1969, but this drops to about $45 \%$ by 2012. Among the U.S. firms, GM suffered the largest loss of market share. While Ford and Chrysler also had declining shares, they had relatively more stable market share profiles compared to GM. The Japanese firms started with a low market share of about 2\% in 1969, and increased to about 35\% by 2012. While all three Japanese firms increased their shares, Toyota was perhaps the most successful in challenging GM and Ford. After 2006, Toyota had a market share around 15\%, which was close to Ford, and was only about 5\% lower than GM in 2010.

Overall, the data show considerable reallocation of market share between the U.S. and Japanese firms, with the later gaining at the expense of the former. The total market share of the three German firms was about 5\% in 1969, declined to about 2\% in the mid-1990s, and then increased to about $7 \%$ by 2012. Volkswagen had a market share of about 5\% in 1969, reached a low of about 0.5\% in 1993, before recovering and increasing to 3\% in 2012. Like the U.S. firms, Volkswagen lost ground to the Japanese firms. In recent years, the high-end luxury brands BMW and Daimler have been at par with the mass-market Volkswagen in their U.S. market shares.

\subsection{Herfindahl Index}

As noted above, the nine firms in our sample have accounted for approximately $91 \%$ of the U.S. sales over our sample period, 1969-2012, representing the dominant portion of the market. In our estimated specification (5), we use individual firms’ market shares as well as a market-wide indicator of competitiveness. For this we construct the Herfindahl-Hirschman Index (HHI). Using data on the nine firms, $H H I_{t}=\sum_{i}\left(s_{i t}^{2}\right), i=1, \ldots, 9$, where $s_{i}$ denotes the firm's market share. ${ }^{32}$ This gives us a time series in HHI for the 44 years in our sample. For the period 1969-1979, the HHI fluctuated around a mean value of about 2,750, with the highest recorded value around 3,000. After 1979, the HHI declines steadily, with the only noticeable difference coming in the 1986-1995 period when it remained relatively flat around 2,000. It declines to a low of about 1,000 in 2012. While the starting value of about 3000 is not particularly high for oligopolistic markets, the decline over the sample period reflects a marked increase in the degree of competition in the market. As the nine

\footnotetext{
${ }^{32}$ As we do not have detailed financial data for the firms over our sample period, we were not able to construct even an approximate measure of profitability. As we noted earlier, since several of the firms are not traded in the U.S. stock markets, or have been traded relatively recently, creating a consistent database of their economic and financial data are not possible.
} 
firms in our sample remain in the market for the full 44-year period, the change in the HHI is largely due to the reallocation of market shares away from the U.S. and towards the Japanese firms.

\section{Estimation Results}

We noted earlier that the empirical evidence on the automobile industry reveals heterogeneity across firms, as well as firms grouped by country of origin. ${ }^{33}$ The panel models we estimate with all nine firms provide us with an overall look at the relationship between competition and patenting. We also estimate sub-sample splits to provide insights onto how the overall estimated relationships vary across the firms grouped by the three countries, U.S., Japan, and Germany. This two-tier estimation strategy may shed additional light on the relationships.

In terms of estimation methods, we are cognizant of the fact that our panel has somewhat different characteristics as compared to typical panels which have large $\mathrm{N}$ and relatively small T. Our full panel has relatively small N (9) and larger T (44). The country-group sub-samples have smaller $\mathrm{N}$ (3), with T (44) remaining the same. Under these characteristics, the GMM estimators may not produce the most efficient parameter estimates, although the precise extent of inefficiency in our case is difficult to determine. To address this, along with the GMM estimates, we also report the more conventional fixed-effects instrumental variables (FEIV) estimates which are less subject to the efficiency problems. By presenting both the GMM and FEIV estimates, we check for the robustness of our inferences. As we note below, our key results are not sensitive to using GMM versus FEIV.

\subsection{Potential Endogeneity}

In specification (5), the $S H R_{t-1}^{i}$ explanatory variable is lagged one period. This reduces any obvious endogeneity issue between a firm's own market share and patents. However, time-series persistence in $P A T_{t}^{i}$ (the dependent variable) and $S H R_{t}^{i}$ may lead to potentially complex reverse causality issues. ${ }^{34}$ To formally examine this, we conducted econometric causality tests. We implement two of the more commonly used tests, by Granger (1969) and Geweke, Meese and Dent (1983). For a given firm, the Granger test uses specification (9) to test for econometric exogeneity:

\footnotetext{
${ }^{33}$ E.g., Lieberman et al. (1990), Lieberman and Demeester (1999), Lieberman and Dhawan (2005), and Lee et al. (2010, 2011).

${ }^{34}$ The general issue of reverse causality has been noted in the literature. Blundell et al. (1999), for example, note that instead of increasing innovations, market shares could be increased by innovation because firms that innovate will grow and therefore have higher market shares.
} 
(9) $\ln \left(S H R_{t}\right)=a+\sum_{m} b_{m} \ln \left(S H R_{t-m}\right)+\sum_{n} c_{n} \ln \left(P A T_{t-n}\right)+u_{t}$.

The test includes m-lags of the firm's own market share (SHR) to capture the variable's own dynamics, and n-lags of the firm's own patents (PAT) to examine reverse causality. The null hypothesis is: $c_{n}=0 \forall n$.

We test for econometric exogeneity by estimating specification (9) firm-by-firm. Our examination of lag lengths showed that two lags were sufficient (i.e., $m=2, n=2$ ); higher-order lags were not significant, and adding them did not change the testing results reported below. For the 9 firms in our sample, the F-static ( $p$-values) from the Granger test are: GM 1.95 (0.156); Ford 0.82 (0.445); Chrysler 0.34 (0.711); Toyota 2.56 (0.091); Honda 3.01 (0.062); Nissan 1.30 (0.284); Volkswagen 0.84 (0.437); BMW 3.51 (0.040); and Daimler 0.07 (0.932). Based on these test results we reject the null for only three firms - Toyota, Honda, and BMW. To conserve space we do not report the results for the Geweke, Meese and Dent (1983) test; ${ }^{35}$ the results were largely similar. To account for the potential endogeneity of SHR for the firms noted above, the dynamic panel estimation methodology we adopt - GMM and FEIV - includes a full set of instruments.

In addition, we also tested for the potential endogeneity of the $\mathrm{HHI}$ in specification (5). The argument here being that significant innovations by a firm can potentially alter the market structure. The HHI in specification (5) is lagged one period, and this reduces any obvious endogeneity issues. We used the Granger and the Geweke et al. procedures to test for potential endogeneity of HHI. The tests do not reject the null of econometric exogeneity of $H H I^{36}$

\footnotetext{
${ }^{35}$ This test uses a different specification structure compared to Granger. Here, the estimated specification is: $\ln \left(P A T_{t}\right)=d+\sum_{k} p_{k} \ln \left(S H R_{t-k}\right)+\sum_{w} q_{w} \ln \left(S H R_{t+w}\right)+\sum_{g} r_{g} \ln \left(P A T_{t-g}\right)+e_{t}$. The specification includes k-lags and $\mathrm{w}$-leads of SHR, and controls for the variable's own dynamics via lagged-dependent variables. The null is: $\mathrm{q}_{\mathrm{w}}=$ $0 \forall$ w; i.e., future values of $S H R$ do not influence current $P A T$.

${ }^{36}$ To conserve space we do not report these results.
} 


\subsection{Own Market Share and HHI}

Results from estimating specification (5) are in Table 5.1. Our key findings are as follows. ${ }^{37}$

\section{Path-dependence of patenting}

The coefficient of the lagged-dependent variable is positive and highly significant, indicating persistence in the path of firms' patents. The estimated elasticities range from approximately 0.58 to 0.81, with the U.S. firms' sample showing the least persistence. As we noted earlier, we also present the FEIV estimates to provide an assurance that our estimates are not being driven by specific estimation methodology. The FEIV estimates are presented in table 5.2. Aside from relatively small quantitative differences, the inferences on the persistence parameter from table 5.2 are similar to those in table 5.1. The lagged-dependent variable elasticities indicate considerable path-dependence in firms’ patenting. This is not surprising as we expect firms’ R\&D processes, and innovation and patenting strategy to show some continuity at least in the short-to-medium term.

\section{Own market share effects}

One of the main variables from theory is firms' own market share. The full-panel estimate of the own market share elasticity is 0.14 , and statistically significant. This implies that for the typical firm in our sample, market share has a positive effect on patents. The country sub-samples reveal heterogeneity in the estimated elasticities. The lowest estimated elasticity is for the group of Japanese firms at approximately 0.13, while the largest elasticity is for the group of U.S. firms at 1.05 . Examining the corresponding own market share FEIV estimates in table 5.2, we find that the majority of the estimates are similar in spirit. The main difference is that while the own market share elasticity for the Japanese group is 0.13 and significant in table 5.1, it drops to 0.07 and insignificant in table 5.2. While there are differences in the quantitative magnitudes, all the signs are positive implying the same directional effect. Overall, we conclude that the GMM and FEIV estimates portray a largely similar picture, and use the GMM estimates for our discussion.

Next, in table 5.3 and table 5.4 we present the quantitative effects. In both these tables, if the underlying GMM coefficient estimate in table 5.1 was statistically insignificant, we assign a value of zero to that effect. In table 5.3 we present the actual change in patents as own market share increases by one standard deviation, starting from its sample mean value. And in table 5.4 we present the

\footnotetext{
${ }^{37}$ As noted in table 5.1, the Sargan statistic (p-values) are: All 332.59 (0.56); U.S. 134.81 (0.11); Japanese 103.93 (0.82); and German 104.50 (0.79). We, therefore, we do not reject the null of valid overidentifying restrictions.
} 
corresponding percentage change in patents if own market share increases by one standard deviation, starting from its sample mean value. Tables 5.3 and 5.4 show that increase (decrease) in own market share results in an increase (decrease) in patents by 106 (or 47.69\%) for U.S. firms. The effects are smaller for the Japanese (23 patents, or 8.1\%) and German (10 patents, or 18.6\%) groups.

Finally, in table 5.5 we present the short-run versus long-run elasticities. Calculation of the long-run elasticities uses the estimates of the short-run elasticities from table 5.1, and the estimate of the patents' path-dependence parameter (the lagged dependent variable). The computed long-run elasticity is an order of magnitude larger than the short-run elasticity, implying that an increase in market share has a markedly larger effect on patenting in the longer-run.

Overall, and based on our discussion in section 2.1 and table 2, our findings are similar in spirit to those in Blundell et al. (1995, 1999), Brouwer and Kleinknecht (1999) and Lee et al. (2011). In addition, our study sheds some light on potential nonlinearities in the relationship between market shares and patenting which we explore in greater detail below.

\section{Market-wide competition (HHI) effects}

Our second key variable from theory is market-wide competition. Our measure is the $\mathrm{HHI}$ - a reduction in $\mathrm{HHI}$ indicates greater competition. The full panel elasticity estimate of -0.25 indicates that greater overall competition in the market increases firms' patenting. Examining the country subsamples, however, reveals marked heterogeneity in the estimated effects. The elasticity is statistically significant, large, and negative for the U.S. group (-1.008), and quantitatively small, negative and insignificant for the Japanese group (-0.083). The elasticity for the German group is quantitatively small, positive and significant (0.064). This implies that the full-panel estimate is essentially being driven by the U.S. effect. The corresponding FEIV estimates in table 5.2 portray a similar picture. The main difference is that for the German group, the estimated elasticity in table 5.1 is 0.064 and significant, while in table 5.2 it is 0.101 and insignificant. Finally, in table 5.6 we present the comparison between the short-run versus long-run elasticity.

The inferences from the $\mathrm{HHI}$ estimates are more mixed as compared to the own market share effects. For HHI, the U.S. group of firms is driving the full-panel estimates; the Japanese group has an insignificant coefficient, and the German group has an opposite sign. In contrast, the own market share elasticities all pointed to the same directional effect, with varying quantitative magnitudes. As before, table 5.3 and 5.4 present the implied quantitative effects. Comparing the actual values of the quantitative effects, a one-standard-deviation change in $\mathrm{HHI}$ has a relatively smaller effect (absolute value) on patents (-13) compared to the firms’ own market share effect (30). 
Our overall full-panel finding - that an increase in market competition stimulates total innovation - is similar in spirit to the results in, for example, Arrow (1962) and Lee and Wilde (1980), and also support the results in Acs and Audretsch (1998), Blundell et al. (1995, 1999), Blind et al. (2006), Aghion et al. (2005), and Hu (2010). Our findings do not support Schumpeter (1934, 1942), Loury (1979), Delbono and Denicolo (1991), and Hashmi (2013), where greater competition reduces innovation. Our findings also do not favor Scherer (1965), Levin and Reiss (1984), Scott (1984), and Levin et al. (1985) where market power had no effect on innovation.

\section{Nonlinearity in the Relationship between Competition and Patents}

Earlier we noted the results in Aghion et al. (2001) and Aghion et al. (2005) predicting a nonlinear, inverted-U shaped, relationship between competition and innovation. Aghion et al. (2005) find some evidence of a nonlinear relationship between competition and patenting. The Aghion et al. (2005, p.703-705) data are fairly aggregated 2-digit industry-level panel with 17 industries covering the time period 1973-1994 (354 industry-year observations in their unbalanced panel). The economic and financial data they use for the U.K. industries are U.K.-based. However, the patents data they use are from the USPTO. ${ }^{38}$ Next they construct a 2-digit industry-average accounting profit-margin. ${ }^{39}$ Then they empirically examine the relationship to find a moderately inverted-U relationship.

Hashmi's (2013) study generates a side-by-side comparison with Aghion et al. (2005). His data for the U.S. cover the years 1976 to 2001, with 116 industries at the 3-digit industry classification (for his 2-digit level there are 20 industries). Using U.S. industry data, he finds a moderately negative relationship between product market competition and patenting, and no evidence to support an inverted-U relationship. For the U.S. data, as competition increases, patenting falls at a mildly diminishing rate. In sharp contrast, the U.K. industry data reveals a mildly inverted U-shaped relationship, and, in general, patenting increases with greater competition.

\footnotetext{
${ }^{38}$ See their data details (p.703-705). They write that their patents data are from the (p.704): “...U. S. patent office, which is where innovations are effectively patented internationally.” But as we see from our data, foreign firms' propensities to patent in the U.S. varies substantively both across firms and over time.

${ }^{39}$ They do not calculate the price-marginal cost Lerner index. Instead they construct a 2-digit industry-average measure of operating profits net of depreciation, provisions and an estimated financial cost of capital divided by sales (p.704-705). It is perhaps useful to note that a 2-digit industry contains myriad types of industries, underlying technologies, and markets, which are often not easily comparable. As an example, the 2-digit category 37 is 'Transportation Equipment' and includes such myriad industries and markets such as 'Motor Vehicle Parts and Accessories', 'Railroad Equipment', 'Boat Building and Repairing', 'Guided Missiles and Space Vehicles', 'Aircraft Engines and Engine Parts', among others. Given such disparate industries, it is difficult to assign meaning to an industry-average measure of profitability.
} 
Aghion et al. (2005) and Hashmi (2013), therefore, show diametrically opposite results. So even with these more sophisticated models and estimated specifications, the evidence on both the sign of the relationship between competition and patenting, and potential nonlinearities, is mixed at best. In some sense, this is similar to the brief summary of the empirical literature in section 2.2 which reveals no conclusive results relating competition to innovation.

There are important differences between the above studies and ours. First, in contrast to the relatively aggregated 2-digit industry level data used by Aghion et al. (2005), our sample contains firm-level data for a single industry. Second, the time period for their study is 1973-1994. In contrast, ours is a much longer period, 1969-2012. Third, they construct an industry-average accounting profit-margin to proxy industry-wide competitiveness. Ours, in contrast, uses the HHI to proxy competitiveness. We do not have financial information for the firms for the full sample period, and therefore cannot construct a Lerner index. Fourth, their studies, being at the 2-digit industry level, do not contain both firms' market shares and industry measure of competitiveness. Given our more disaggregated study, we control for both firms' market shares and HHI, allowing us to examine the conditional relationships. Fifth, models like Aghion et al. may often be difficult to test as the degree of competition may not traverse the full spectrum - high degree of competition to near monopoly. The U.S. automobile market we study essentially moves from a tighter oligopoly (higher HHI, when the U.S. firms had dominant market share) to a looser oligopoly (lower HHI, with the expansion of the Japanese firms' market shares). Given these substantive differences in data characteristics, direct comparisons between their study and ours is not possible.

Our estimated specification (5) is log-linear, and therefore builds in non-linearity in levels. Using the full-panel estimated coefficients from table 5 (column 1), in figure 4 panel (a) we plot the estimated relationship between firms’ market shares and patents, and panel (b) the estimated relationship between HHI and patents. From panel (a) we see that the estimated patents increase with market shares, and the curvature is much sharper initially. Over the range of firms' market shares observed in the data (from about 1\% to 46\%), the estimated patents go from about 75 (per year) to 225 (per year). For the HHI effect in panel (b), the curvature is very mild, and over the range of HHI observations in the data (from about 1,000 to 3,000), the estimated patents go from about 212 to 166. Consistent with the calculations presented in tables 5.3 and 5.4, the quantitative effect on patents is much smaller for the HHI as compared to the market share effect.

To provide a visual comparison, in figure $\mathbf{5}$ we present the figure from Hashmi which shows the side-by-side comparison using U.K. and U.S. 2-digit industry data. As we noted above, our results are not directly comparable to either Hashmi or Aghion et al. (2005) due to the substantial 
differences in data characteristics. Our HHI results - which shows that increase in market competition leads to increase in patenting - is closer to the findings by Aghion et al. However, if we look at the estimated relationship by Hashmi for the U.S. data, after the initial drop, there appears to be a flat relationship between his measure of competition and patents. In our case (figure 4, panel b), the estimated patents-HHI line also has a very weak gradient.

Overall, we find evidence of non-linearity in the relationship between competition and patenting, and that an increase in market-wide competition (using $\mathrm{HHI}$ ) results in marginally greater patenting. As we noted above, our data are not comparable to either Aghion et al. (2005) or Hashmi (2013). In addition, our estimated specifications are richer that the above studies as they include controls for both firms’ market shares and HHI, along with other controls.

\section{Other control variables}

We briefly comment on our set of control variables. First, the environmental variable Enviro1 (1969-1974) is always positive. The coefficient for the Japanese group of firms is positive and significant, while the coefficient estimate is about as large for the U.S. firms but just below the 10\% significance level. The coefficient is very small and insignificant for the German group. The general positive effect tallies with previous findings that the Clean Air Act increased innovation and patenting (e.g., Lee et al., 2010, 2011). The Enviro2 effect is mixed: positive and significant for the U.S. group, but negative and significant for the Japanese group. It is insignificant for the German group of firms. Our motivation for including the Enviro(.) effects was to control for potential environmental patents related findings of Lee et al. (2010, 2011). As we noted in section 3.1, our study is different from Lee at al. in that our focus is on the relationship between competition and total patents, and our sample period is also very different. However, our overall findings on Enviro(.) are similar in spirit to Lee at al. in that Enviro(.) matters, but the estimated effects vary across groups of firms, as well as across time periods.

Second, the Bankruptcy variable was designed to control for GM's problems during 20092012. The estimates shows that GM's patenting fell dramatically during the bankruptcy period. Given the dramatic internal organizational restructuring during this period, and potential financial problems, this is perhaps not surprising.

Third, the Merger variable was designed to control for any residual effects of the merger between Daimler and Chrysler that were not addressed in our adjustments to the data to create a merger-adjusted continuous time-series for Chrysler and Daimler. We find that the merger increased patenting in the U.S. group, implying an increase in Chrysler's patents at an elasticity of 0.24 . There 
is no statistically significant effect for the group of German firms, implying that there were no additional effects on Daimler. Overall, the merger appeared to have provided some synergies which lead to an increase in patenting for the two firms, but the effects were not symmetric.

Fourth, voluntary export restraints appear to have had no effect on the patenting activity of either U.S. or Japanese groups - the two groups affected by the VER. There is a negative effect on the German group, but the quantitative effect is very small. We did not have a clear prior on this variable, but included this as a control as it was an important event in the U.S. automobile market. Fifth, we included GDP growth to account for potential cyclical effects on innovation. GDP growth appears to be positively related to firms’ patenting. The pro-cyclical pattern is statistically significant for the U.S. and Japanese group of firms with rather small estimated elasticities. The elasticity for the German group is not significant. This broad pro-cyclicality of innovation activities appears consistent with several other studies in the literature (e.g., Geroski and Walter, 1995; Barlevy, 2007; Guellec and Ioannidis (1997), and Ouyang 2011).

\section{Checks of robustness}

Our estimation already builds in several checks and controls to ensure confidence that we are picking up meaningful parameter estimates for firms’ own market share and market-wide competitiveness effects. For example: (i) we tested our market share and HHI variables for endogeneity, and the estimation accounts for potential endogeneity; (ii) we presented alternative sets of estimates using GMM and fixed-effects instrumental variables procedures; and (iii) the estimated specification (5) contains a vector of control variables spanning environmental regulations, voluntary export restraints, the Daimler-Chrysler merger, GM's bankruptcy, and aggregate business cycle conditions (GDP growth). Below we report two additional checks.

First, one potential shortcoming of our estimates reported in table 5.1 is that we could not include year-time dummies due to collinearity problems. The extent of this shortcoming, however, is not clear as we do have other important controls that affect the firms, such as environmental regulations, voluntary export restraints, and macroeconomic business cycles (GDP growth). To take another look at this issue, we carried out the following estimation by: (a) dropping Enviro1, Enviro2 and VER from specification (5); and (b) adding non-overlapping 4-year period dummies 1970-73, 1974-77, ...., 2006-09, 2010-12. The last dummy is for 3 years as 2012 is the last year in the sample. Our objective in including these period dummies was to, for example: (i) mimic year-time dummies, but with extended periods for each dummy; (ii) have the set of dummies cover the full sample period to capture any effects over time that could be related to, for example, environmental standards 
affecting all firms (a strategy similar to that employed in Lee et al. (2011); (iii) potentially control for any broad technological shifts that may have affected the automobile industry over time; and (iv) control for overall changes in the physical presence of foreign producers in the U.S. in terms of opening manufacturing plants, design studios, etc. Many of these operations tend to be staffed by Americans rather than Japanese, and they may give rise to, for example, intermingling of corporate cultures, management styles and innovation related spillovers. We also experimented with varying the time periods for the dummies noted in (b) above (for example, 3 or 5 year periods), and these did not affect our inferences noted below. With these set of changes the coefficient (std. error) of $S H R_{t-1}^{i}$ was $0.126(0.061)$. Given the standard error, this is statistically the same as the estimate reported in table 5.1 of 0.141 (0.060). The coefficient (s.e.) of $H H I_{t-1}$ was -0.730 (0.305); this is in contrast to 0.247 (0.087) reported in table 5.1. While the HHI coefficient is quantitatively smaller, the qualitative inferences remain the same.

Second, given that we have a relatively long sample period of 44 years, a reasonable question to ask is whether the estimated slope coefficients of our main variables of interest, $S H R_{t-1}^{i}$ and $H H I_{t-1}$, are stable over time. To examine this we segmented the sample into two 22-year periods, and reestimated specification (5) for each sub-period. To formally test, we calculated the z-values ( $p$ values $)^{40}$ which are 0.04 (0.966) for $S H R_{t-1}^{i}$ and 0.17 (0.868) for $H H I_{t-1}$. Based on our tests, we could not reject the null for the equality of coefficients across the two sub-periods.

\subsection{Own Market Share and Rivals’ Shares}

As we noted in section 3.2, our objective here is to examine if firms' patenting responses vary across specific rival(s). For example, does GM care more about the market shares of its U.S. competitors or Japanese? The GMM estimation results for specification (8) are presented in Table 6.1. ${ }^{41}$ To conserve space, we focus our discussion of estimation results on the main variables of interest related to market shares, and only briefly comment on the control variables. ${ }^{42}$

\footnotetext{
${ }^{40}$ The z-statistic is based on Paternoster et al. (1998) who refine the test in Clogg et al. (1995). This allows testing the equality of coefficients in different models when one of the models is nested in the other. This is true in our case as some of the variables - such as Enviro1, Enviro1, VER, Merger and Bankruptcy - are relevant for the sub-periods used for testing the equality of coefficients, 1969-1990 or 1991-2012. We also carried out an alternative test by reestimating specification (5) by adding a dummy variable to delineate the two sub-periods, as well as interacting this dummy with $S H R$ and $H H I$, our main variables of interest. Using this procedure and testing resulted in the same conclusion - that we cannot reject the null of equality of coefficients.

${ }^{41}$ To conserve space, we do not present the fixed-effects IV estimates for these set of results. The results were largely similar, as was the case for tables 5.1 and 5.2.

${ }^{42}$ As noted in table 6.1, the Sargan statistic (p-values) are as follows: All 329.17 (0.610); U.S. 131.80 (0.122); Japanese 102.32 (0.814); and German 101.58 (0.810). We do not reject the null of valid overidentifying restrictions.
} 


\section{Own market share effects}

The estimated own market share elasticities are highly significant, as they were in table 5.1. At an estimated elasticity of 0.141 , the coefficient on the Japanese sample is about the same as in table 5.1. The main difference lies for the U.S. firms where the estimated elasticity of 0.755 from table 6.1 is about 25\% smaller less than that from table 5.1 (1.048). The estimate for the German sample of 0.185 (table 6.1) is borderline insignificant; in table 5.1 this coefficient was 0.245 and significant. The implied quantitative effects are presented in Table 6.2 (actual changes) and Table 6.3 (percentage changes). Overall, the inferences related to firms' own market share remain the same even though we dropped HHI and included three categories of rivals’ market share variables.

\section{Rivals’ market shares}

In this section we discuss the effects related to the rivals, segmented into three groups: (i) own-country; (ii) other-country:main; and (iii) other-country:other. To note again, specification (8) is different from (5) in that we drop HHI and add three categories of rivals' market share variables. ${ }^{43}$

The own-country rivals' coefficients in table 6.1 are all negative. This indicates that as firms' own-country rivals’ market shares increase (decrease), firms’ patenting decreases (increases). But the estimated elasticity is statistically significant only for the U.S. group -0.365 . The elasticity for the Japanese and German groups are -0.139 and -0.085 , but statistically insignificant. The implied quantitative effects are presented in table 6.2 (actual changes) and table 6.3 (percentage changes). At broad brush, these estimates indicate that, aside from the U.S. firms, own-country rivals' market shares do not matter much in their patenting response.

For the other-country 'main' rivals, the overall panel estimate from column 1 is positive (0.106) and significant. This indicates that as firms' other-country primary rivals' market shares increase (decrease), firms increase (decrease) patenting. However, there are important differences across the groups. The estimated elasticities are positive the U.S. (0.274) and German (0.168) groups and significant. In contrast, it is negative (-0.218) and insignificant for the Japanese group. This indicates that unlike the U.S. and German groups, the Japanese group’s patenting does not appear to be affected by their main rivals' market shares. The overall result of a positive and significant effect (column 1) is being driven by the U.S. and German groups.

\footnotetext{
${ }^{43}$ In the panel, the correlation between firms' market shares and own-country:main rivals' shares is -0.3. Earlier we had noted that the correlation between firms' market shares and HHI was 0.02. None of these correlations are high to cause collinearity problems.
} 
For the other-country 'other' or secondary rivals, while the coefficients are all positive, none of the country groups estimates are statistically significant. But the coefficient for the full panel (column 1) is positive (0.106) and significant. One reason for this could be that the efficiency gains from having a larger number of observations in the full panel is leading to a more precise estimate.

From the results presented in table 6.1, an increase in other-country (foreign) rivals' market shares lead to increase in firms' patenting, but there is considerable heterogeneity in the quantitative magnitudes as well as the precision with which these effects are measured. In contrast, the owncountry estimates are negative, but statistically significant only for the U.S. group. Looking at the big picture scenario, and focusing on the full-panel results in column 1, it appears that the primary threat the firms perceive to their competitive positions comes from their (main) foreign rivals, and this is what induces them to increase their innovative activity as measured by patents.

Our overall finding - that an increase in primary threat from their (main) foreign rivals will lead to more patents - is similar in spirit to the hypothesis of competitive threat by $\mathrm{Hu}$ (2010). These results are also consistent with the influence of HHI in Table 5.1 that market competition has no statistically significant effect on the Japanese group, but it increases the patenting of the U.S. group and marginally affects the German group.

\section{Other control variables}

We discuss these results very briefly. The estimates of the coefficients on the laggeddependent variables are very similar to those reported in table 5.1. This implies that the estimated innovation and patenting path-dependence effect is not influenced by the inclusion of rivals' market share variables we introduce in table 6.1. The full-panel Enviro1 coefficient is positive and significant as in table 5.1. For the U.S. it was positive and close to $10 \%$ significance in table 5.1; now it shows a quantitatively larger and statistically significant effect. The results for the Japanese group is opposite: it was positive and significant in table 5.1, but is insignificant in table 6.1. The estimate for the German group remains insignificant. The Enviro2 effect in table 6.1 is uniformly insignificant. The estimates related to Bankruptcy, Merger, and GDP growth are very similar across tables 5.1 and 6.1. The estimated VER elasticities now show a statistically significant decline in U.S. firms’ patenting, and a statistically positive effect on Japanese firms’ patenting.

\section{Concluding Remarks}

We use firm-level data to examine the relationship between competition and patenting in the U.S. automobile market. The combination of the U.S. market's economic importance, market 
dynamics, and the significant intertemporal fluctuations in firms' market shares and patents make this an interesting market to examine the link between competition and innovation. ${ }^{44}$

Based on dynamic panel data estimates, our main findings are as follows. First, we find that an increase in firms' market shares leads to an increase in patenting, and the relationship is moderately non-linear. Second, we find that higher market-wide competition results in an increase in patenting, and the relationship is weakly non-linear. Our results on market-wide competition appear similar in spirit to those of Aghion et al. (2005), although our firm-level data and control variables are very different from their aggregated 2-digit industry). Third, in a horse-race between firms’ market share and market-wide competitiveness, the (absolute) quantitative impact on patents is larger for firms' market share effect. Due to our disaggregated firm-level data we were able to control for both firms' market share as well as market-wide competitiveness. The typical study in this literature does not control for both these effects. In this sense our empirical specification has a more complete set of controls.

In other results, we find that patents are procyclical, but the quantitative effect is very small. GM's bankruptcy, representing an extreme case of firm-specific decline in fortunes, results in a sharp drop in a patenting. The Daimler Chrysler merger, representing the combination of two very large and prominent firms, results in a relatively small increase in patenting, primarily attributable to Chrysler.

Finally, we find that there is considerable heterogeneity in the estimated effects by firms grouped by countries. This heterogeneity appears consistent with some of the previous findings in the literature which reveal marked differences across the automobile firms' organizational structure, degree of vertical integration, lean production, responses to environmental regulations, among other attributes. $^{45}$ This heterogeneity implies that no one class of theoretical models noted in section 2.1 finds broad support. At least at face value, our results seem consistent with the "Resource-Based View" of the firm, which has been widely used in the Management literature to explain idiosyncratic firm-specific responses by automobile firms to common shocks as well as firm-specific shocks. ${ }^{46}$

\footnotetext{
${ }^{44}$ As we noted in section 2.1, a substantive theoretical literature has provided deep insights into this relationship. Perhaps the most recent and sophisticated models exploring this relationship are by Aghion et al. (2001) and Aghion et al. (2005). Overall, the theoretical literature is inconclusive in terms of the 'sign' of the relationship. The empirical literature, reflects this theoretical ambiguity, and has produced widely differing estimates. In recent years, while Aghion et al. (2005) find evidence of non-linearity using aggregated U.K. 2-digit industry data, Hashmi (2013) using U.S. industry data finds results that are diametrically opposite to Aghion et al. (2005).

${ }^{45}$ E.g., Lieberman et al. (1990), Lieberman and Demeester (1999), Lieberman and Dhawan (2005), Lee et al. (2010, 2011).

${ }^{46}$ See previous footnote.
} 


\section{References}

ACs, Z. J., and D. B. AudRETSCH (1988): "Innovation in Large and Small Firms: An Empirical Analysis," The American Economic Review, 78, 678-690.

Aghion, P., N. Berman, L. Eymard, P. Askenazy, and G. Cette (2012): "Credit Constraints and the Cyclicality of R\&D Investment: Evidence from France," Journal of the European Economic Association, 10, 1001-1024.

Aghion, P., N. Bloom, R. Blundell, R. Griffith, and P. HowitT (2005): "Competition and Innovation: An Inverted-U Relationship," The Quarterly Journal of Economics, 120, 701728.

Aghion, P., C. Harris, P. HowitT, and J. ViCKers (2001): "Competition, Imitation and Growth with Step-by-Step Innovation," The Review of Economic Studies, 68, 467-492.

Ahn, S. (2002): "Competition, Innovation and Productivity Growth: A Review of Theory and Evidence," OECD Economics Department Eorking Papers, No. 317, OECD Publishing.

AnTon, J. J., and D. A. YAO (2004): "Little Patents and Big Secrets: Managing Intellectual Property," The RAND Journal of Economics, 35, 1-22.

ARROW, K. (1962): "Economic Welfare and the Allocation of Resources for Invention," in The Rate and Direction of Inventive Activity: Economic and Social Factors, ed. by U.N. Bureau: UMI, 609-626.

BARLEVy, G. (2007): "On the Cyclicality of Research and Development," The American Economic Review, 97, 1131-1164.

Blind, K., J. EDLER, R. Frietsch, and U. SchmOCH (2006): "Motives to Patent: Empirical Evidence from Germany," Research Policy, 35, 655-672.

Blundell, R., R. GRIFFITH, and J. V. REENEN (1995): "Dynamic Count Data Models of Technological Innovation," The Economic Journal, 105, 333-344.

Blundell, R., R. GRIfFith, and J. V. ReEnEN (1999): "Market Share, Market Value and Innovation in a Panel of British Manufacturing Firms," The Review of Economic Studies, 66, 529-554.

Brouwer, E., and A. KleinKNecht (1999): "Innovative Output, and a Firm's Propensity to Patent: An Exploration of CIS Micro Data," Research Policy, 28, 615-624.

Cockburn, I. M., and M. J. MAcGARvie (2009): "Patents, Thickets and the Financing of Early-Stage Firms: Evidence from the Software Industry," Journal of Economics \& Management Strategy, 18, 729-773.

Cohen, W. M., A. Goto, A. Nagata, R. R. Nelson, and J. P. Walsh (2002): "R\&D Spillovers, Patents and the Incentives to Innovate in Japan and the United States," Research Policy, 31, 1349-1367.

Cohen, W. M., and R. C. Levin (1989): "Empirical Studies of Innovation and Market Sturcture," in Handbook of Industrial Organization, ed. by R. Schmalensee, and R. Willig: Elsevier, 10591107.

Delbono, F., and V. Denicolo (1991): "Incentives to Innovate in a Cournot Oligopoly," The Quarterly Journal of Economics, 106, 951-961.

EISNER, R., R. H. StRotZ, and G. R. Post (1963): Determinants of Business Investment. PrenticeHall.

FALK, M. (2006): "What Drives Business Research and Development (R\&D) Intensity across Organisation for Economic Co-Operation and Development (Oecd) Countries?," Applied Economics, 38, 533-547. 
Geroski, P. A., and C. F. WAlters (1995): "Innovative Activity over the Business Cycle," The Economic Journal, 105, 916-928.

GeweKe, J., R. MEeSE, and W. Dent (1983): "Comparing Alternative Tests of Causality in Temporal Systems: Analytic Results and Experimental Evidence," Journal of Econometrics, 21, 161194.

GILBERT, R. (2006): "Looking for Mr. Schumpeter: Where Are We in the Competition-Innovation Debate?," in Innovation Policy and the Economy, Volume 6: The MIT Press, 159-215.

Granger, C. W. J. (1969): "Investigating Causal Relations by Econometric Models and CrossSpectral Methods," Econometrica, 37, 424-438.

GUELLEC, D., and E. IOANNIDIS (1997): "Causes of Fluctuations in R\&D Expenditures: A Quantitative Analysis," OECD Economic Studies, 123-138.

Hall, B., C. Helmers, G. Von Graevenitz, and C. Rosazza-Bondibene (2012): "A Study of Patent Thickets," Final report prepared for the UK Intellectual Property Office.

Hall, B. H., and R. H. ZiedOnis (2001): "The Patent Paradox Revisited: An Empirical Study of Patenting in the U.S. Semiconductor Industry, 1979-1995," The RAND Journal of Economics, 32, 101-128.

HAshmi, A. R. (2013): "Competition and Innovation: The Inverted-U Relationship Revisited," Review of Economics and Statistics, 95, 1653-1668.

Hashmi, A. R., and J. V. BiesebroecK (2006): "Competition and Innovation: A Dynamic Analysis of the US Automobile Industry," Concordia University, Montreal, 25-28.

Hausman, J., B. H. Hall, and Z. GriLIChes (1984): "Econometric Models for Count Data with an Application to the Patents-R \& D Relationship," Econometrica, 52, 909-938.

HendRY, D. F., A. R. PAgAn, and J. D. SARgan (1984): "Dynamic Specification," Handbook of econometrics, 2, 1023-1100.

Holt, C., F. Modigliani, J. F. Muth, and H. A. Simon (1960): "Production Planning, Inventories, and Workforce," Prentice Hall, New York.

Hu, A. G. (2010): "Propensity to Patent, Competition and China's Foreign Patenting Surge," Research Policy, 39, 985-993.

IWASA, T., and H. ODAGIRI (2004): "Overseas R\&D, Knowledge Sourcing, and Patenting: An Empirical Study of Japanese R\&D Investment in the US," Research Policy, 33, 807-828.

JANSEN, J. (2011): "On Competition and the Strategic Management of Intellectual Property in Oligopoly," Journal of Economics \& Management Strategy, 20, 1043-1072.

Jorgenson, D. W. (1986): "Econometric Methods for Modeling Producer Behavior," Handbook of econometrics, 3, 1841-1915.

Kennan, J. (1979): "The Estimation of Partial Adjustment Models with Rational Expectations," Econometrica, 47, 1441-1455.

KIM, Y. K., K. LEE, W. G. PARK, and K. CHOO (2012): "Appropriate Intellectual Property Protection and Economic Growth in Countries at Different Levels of Development," Research Policy, 41, 358-375.

Kondo, M. (1999): "R\&D Dynamics of Creating Patents in the Japanese Industry," Research Policy, 28, 587-600.

Kortum, S., and J. Lerner (1999): "What Is Behind the Recent Surge in Patenting?," Research Policy, 28, 1-22.

Kortum, S., and J. LeRner (2000): "Assessing the Contribution of Venture Capital to Innovation," The RAND Journal of Economics, 31, 674-692.

LeE, J., F. M. Veloso, and D. A. Hounshell (2011): "Linking Induced Technological Change, and Environmental Regulation: Evidence from Patenting in the U.S. Auto Industry," Research Policy, 40, 1240-1252. 
Lee, J., F. M. Veloso, D. A. Hounshell, and E. S. Rubin (2010): "Forcing Technological Change: A Case of Automobile Emissions Control Technology Development in the U.S.," Technovation, 30, 249-264.

LEE, T., and L. L. WILDE (1980): "Market Structure and Innovation: A Reformulation," The Quarterly Journal of Economics, 94, 429-436.

LEVIN, R., and P. C. REISS (1984): "Tests of a Schumpeterian Model of R\&D and Market Structure," in $R \& D$, Patents, and Productivity: University of Chicago Press, 175-208.

Levin, R. C., W. M. Cohen, and D. C. Mowery (1985): "R\&D Appropriability, Opportunity, and Market Structure: New Evidence on Some Schumpeterian Hypotheses," The American Economic Review, 20-24.

LieBerman, M. B., and L. Demeester (1999): "Inventory Reduction and Productivity Growth: Linkages in the Japanese Automotive Industry," Management Science, 45, 466-485.

Lieberman, M. B., and R. DhawAn (2005): "Assessing the Resource Base of Japanese and U.S. Auto Producers: A Stochastic Frontier Production Function Approach," Management Science, 51, 1060-1075.

LiEBERMAN, M. B., L. J. LAU, and M. D. Williams (1990): "Firm-Level Productivity and Management Influence: A Comparison of U.S. And Japanese Automobile Producers," Management Science, 36, 1193-1215.

LoKshin, B., and P. Mohnen (2012): "How Effective Are Level-Based R\&D Tax Credits? Evidence from the Netherlands," Applied Economics, 44, 1527-1538.

LOURY, G. C. (1979): "Market Structure and Innovation," The Quarterly Journal of Economics, 93, 395-410.

Mosel, M. (2011): "Big Patent, Small Secrets: How Firms Protect Inventions When R\&D Outcome Is Heterogeneous," BGPE Discussion Paper, No. 105.

Noel, M., and M. SchanKerman (2013): "Strategic Patenting and Software Innovation," The Journal of Industrial Economics, 61, 481-520.

OuYANG, M. (2011): "On the Cyclicality of R\&D," Review of Economics and Statistics, 93, 542-553.

Paternoster, R., R. Brame, P. Mazerolle, and A. Piquero (1998): "Using the Correct Statistical Test for the Equality of Regression Coefficients," Criminology, 36, 859.

SARgENT, T. J. (1978): "Estimation of Dynamic Labor Demand Schedules under Rational Expectations," Journal of Political Economy, 86, 1009-1044.

Scherer, F. M. (1965): "Firm Size, Market Structure, Opportunity, and the Output of Patented Inventions," The American Economic Review, 55, 1097-1125.

SCHERER, F. M. (1967): "Market Structure and the Employment of Scientists and Engineers," The American Economic Review, 57, 524-531.

SCHumpeter, J. A. (1934): The Theory of Economic Development. Harvard University Press.

SChumpeter, J. A. (1942): Capitalism, Socialism, and Democracy. New York: Harper.

ScotT, J. (1984): "Firm Versus Industry Variability in R\&D Intensity," in R\&D, Patents, and Productivity: University of Chicago Press, 233-248.

vON Graevenitz, G., S. WAGNER, and D. HARHOFF (2013): "Incidence and Growth of Patent Thickets: The Impact of Technological Opportunities and Complexity," The Journal of Industrial Economics, 61, 521-563. 
Figure 1. Automobile Firms' USPTO Patents - Grouped by Country

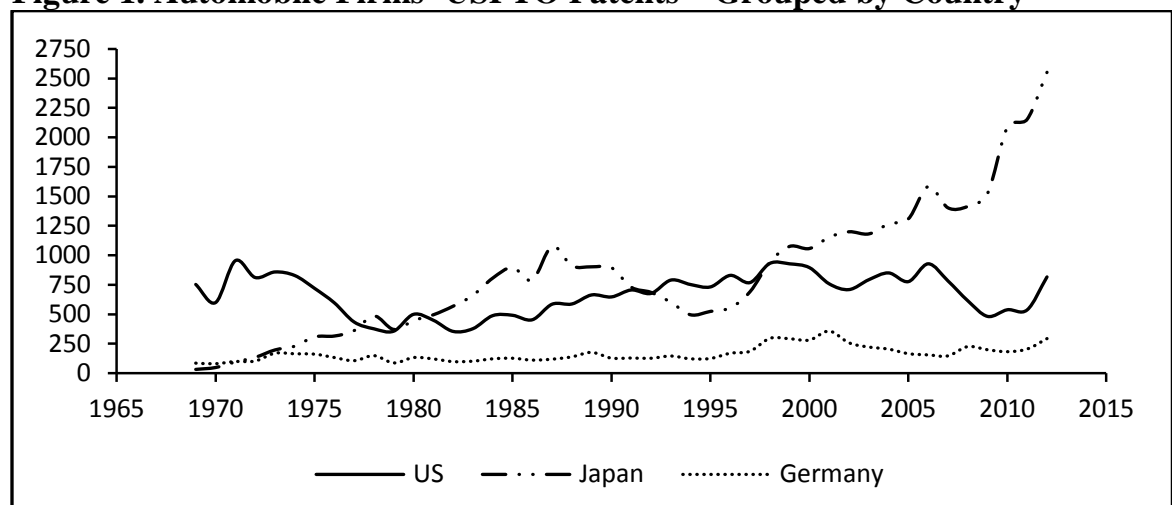

Notes: The data for the US are the sum of USPTO patents for GM, Ford and Chrysler. Japan, for Toyota, Honda and Nissan. Germany, for Volkswagen, BMW and Daimler.

Figure 2. OECD Country Total Triadic Patents - All Patents

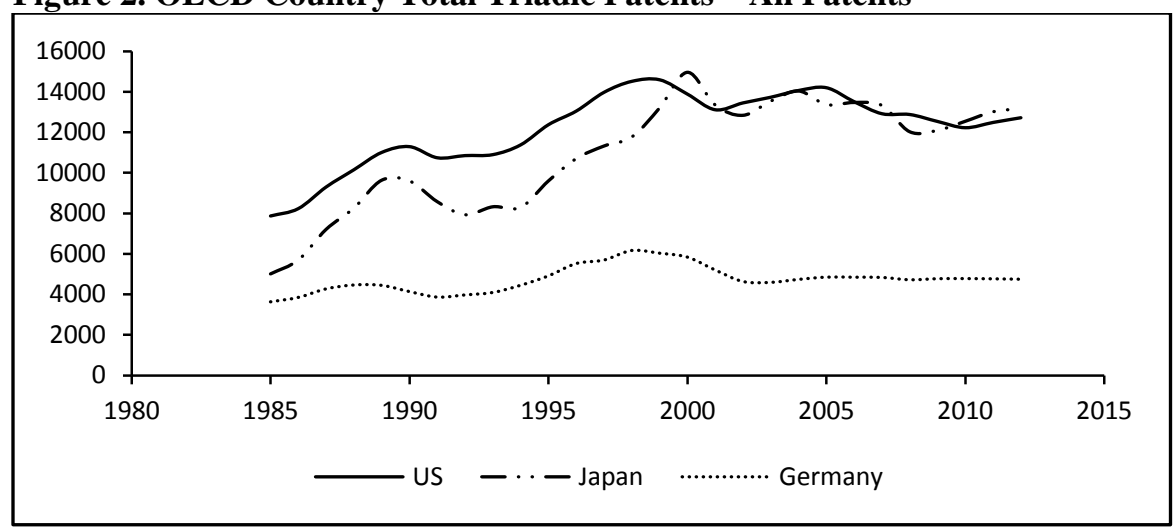

Notes: The country triadic patent totals data are from the OECD patents database (1985-2012). These are all patents by country (not just automobile).

Figure 3. Automobile Firms' U.S. Market Shares - Grouped by Country

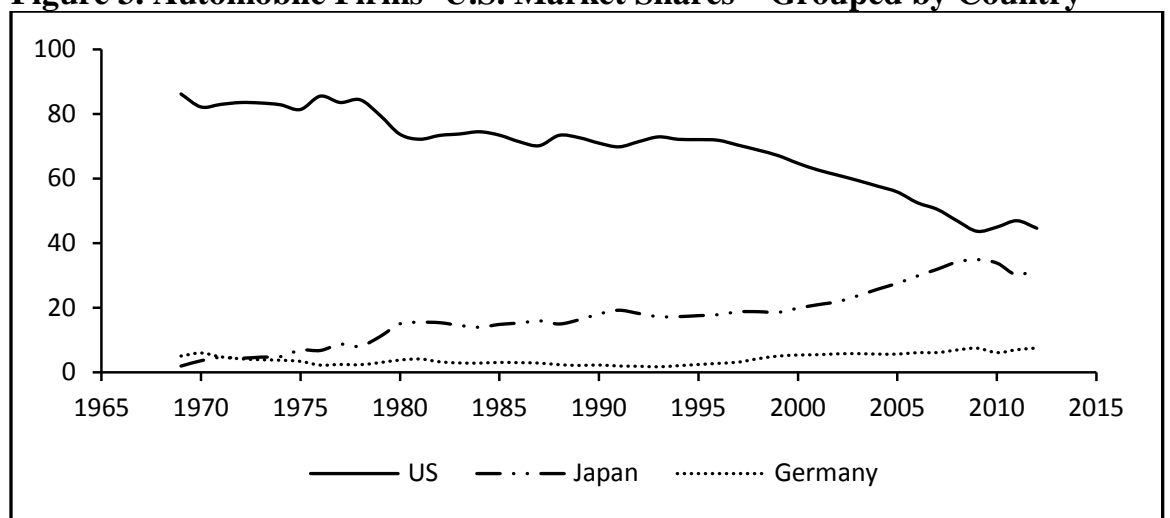

Notes: The data for the US are the sum of market shares for GM, Ford and Chrysler. Japan, for Toyota, Honda and Nissan. Germany, for Volkswagen, BMW and Daimler. 
Figure 4. Market Share, HHI and Estimated Patents

Panel (a): Market Share

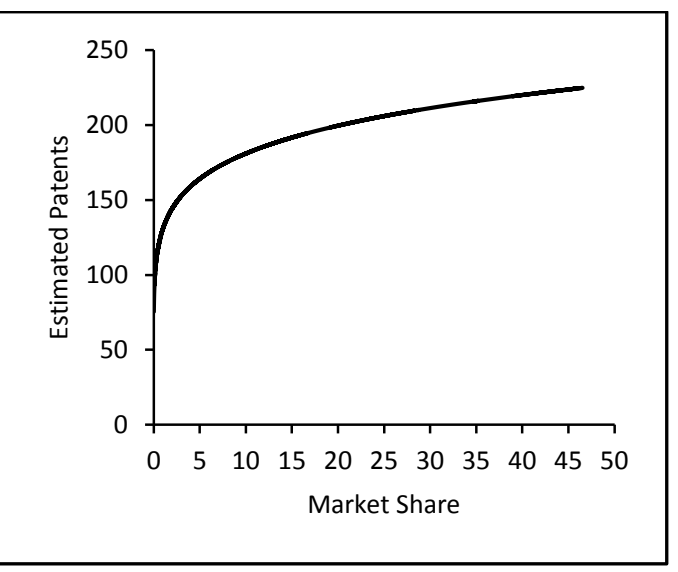

Panel (b): HHI

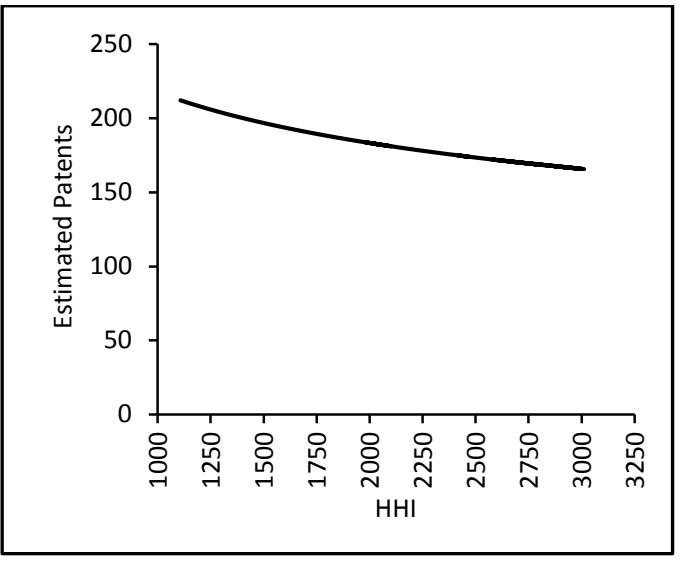

Note: In panel (a), estimated patents increase as firms' market shares increase. In panel (b), estimated patents increase as HHI decreases - implying that as market-wide competitiveness increases (lower HHI), patenting increases. The above figures reflect the calculations from tables 5.3 and 5.4 where we see that the estimated quantitative effects for firms' market shares are larger than for HHI.

Figure 5. Findings by Hashmi (2013).

Figure 1.-Empirical Results on the Three Predictions: ABBGH Data Versus US Data
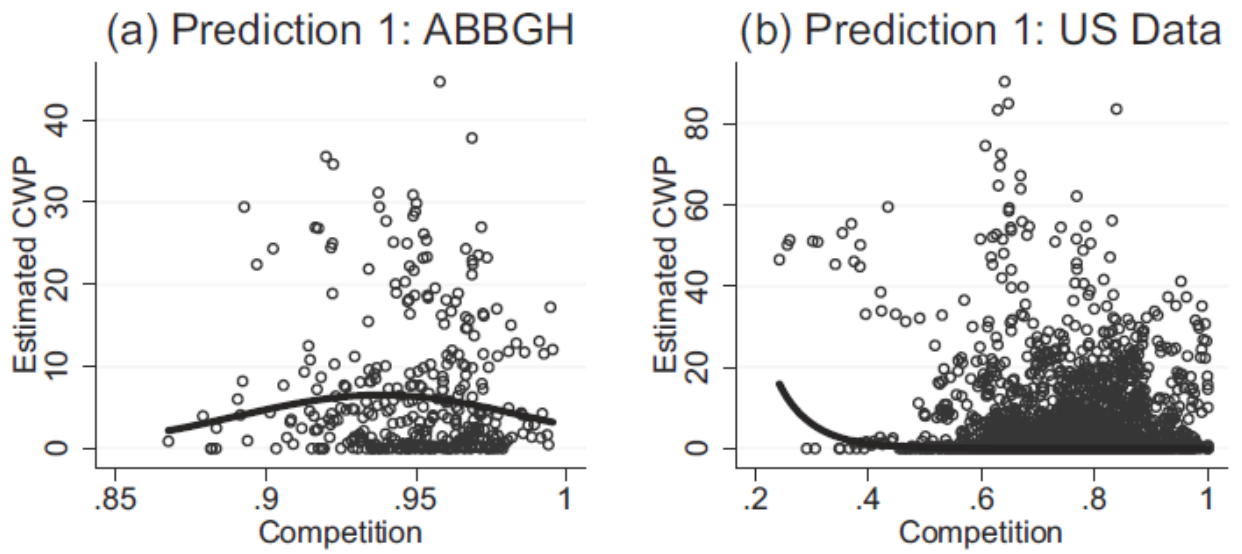

Note: This figure is reproduced from Hashmi (2013, p. 1659, Figure 1). The solid lines above represent the estimated relationship: Panel (a) is based on the U.K. data used in Aghion et al. (2005, ABBGH); and Panel (b) is based on the U.S. data. As noted in Hashmi (p.1655): "Prediction 1. There is an inverted-U relationship between product market competition and innovation.” (This is based on proposition 2 in Aghion et al., 2005, p.715.) The findings from the U.S. and U.K. data are diametrically opposite. Further, if we look at the U.S. figure, the estimated line is virtually flat above their competition measure 0.4. 
Table 1. Selected Theoretical Papers: Relationship between Competition and Innovation

\begin{tabular}{|l|l|l|l|}
\hline Paper & Innovation Variable(s) & $\begin{array}{l}\text { Competition Variable(s) and (or) } \\
\text { Market Structure }\end{array}$ & Results(s) \\
\hline Aghion et al. (2001) & R\&D & $\begin{array}{l}\text { Product-market competition. } \\
\text { Bertrand }\end{array}$ & $\begin{array}{l}\text { Negative: Schumpeterian effect } \\
\text { Positive: escape competition }\end{array}$ \\
\hline Aghion et al. (2005) & Patents & $\begin{array}{l}\text { Industry price-cost margins } \\
\text { Bertrand }\end{array}$ & Non-linear, Inverted U-shaped \\
\hline Arrow (1962) & General Innovation & $\begin{array}{l}\text { Conopoly. Perfect competition. } \\
\text { Cournot }\end{array}$ & Positive \\
\hline Anton and Yao (2004) & Patents & $\begin{array}{l}\text { Number of rivals } \\
\text { Cournot oligopoly }\end{array}$ & Patent small innovations \\
\hline Delbono and Denicolo (1991) & R\&D & $\begin{array}{l}\text { Number of rivals } \\
\text { Cournot. Bertrand }\end{array}$ & Negative \\
\hline Jansen (2011) & Patents & Number of rivals & $\begin{array}{l}\text { Cournot: positive. } \\
\text { Bertrand: negative. }\end{array}$ \\
\hline Lee and Wilde (1980) & R\&D & Number of rivals & Positive \\
\hline Loury (1979) & R\&D & $\begin{array}{l}\text { Cost reduction and profits } \\
\text { Bertrand }\end{array}$ & Negative \\
\hline Mosel (2011) & Patents. R\&D & Monopoly. Perfect competition. & Negative \\
\hline Schumpeter (1942) & General innovation & & \\
\hline
\end{tabular}

Table 2. Selected Empirical Papers: Relationship between Competition and Innovation

\begin{tabular}{|c|c|c|c|}
\hline \multicolumn{4}{|c|}{ Panel A: Firm Specific Shares and Related Variables } \\
\hline Paper & Innovation Variables(s) & Market Performance Variable(s) & Results(s) \\
\hline Blundell et al. (1995) & Commercialized innovations & Market share & Positive \\
\hline Blundell et al. (1999) & $\begin{array}{l}\text { Commercialized innovations } \\
\text { Patents }\end{array}$ & Market share & Positive \\
\hline Brouwer \& Kleinknecht (1999) & Patents & Sales & Positive \\
\hline $\mathrm{Hu}(2010)$ & Patents & Imports & Insignificant \\
\hline Hashmi \& Biesebroeck (2006) & R\&D & Profit margin. Market share & Non-linear, inverted-U shaped \\
\hline Lee et al. (2011) & Patents & Market share & Positive \\
\hline Noel \& Schankerman (2013) & R\&D & Sales & Effect varies across periods \\
\hline Scherer (1965) & Patents & Sales & Positive, non-linear \\
\hline \multicolumn{4}{|c|}{ Panel B: Market-Wide Competition and Related Variables } \\
\hline Paper & Innovation Variables(s) & Competition Variable(s) & Results(s) \\
\hline Acs \& Audretsch (1988) & Patents & Concentration ratio & Negative \\
\hline Aghion et al. (2005) & Patents & Industry price-cost margins & Non-linear, inverted-U shaped \\
\hline Blundell et al. (1995) & Commercialized innovations & Concentration ratio & Negative \\
\hline Blundell et al. (1999) & $\begin{array}{l}\text { Commercialized innovations } \\
\text { Patents }\end{array}$ & Concentration ratio & Negative \\
\hline Blind et al. (2006) & Patents & Competition intensity & Positive \\
\hline $\mathrm{Hu}(2010)$ & Patents & Competing imports & Positive \\
\hline Hashmi (2013) & Patents & Price cost margins & Negative \\
\hline Levin \& Reiss (1984) & R\&D & HHI & Insignificant \\
\hline Levin et al. (1985) & R\&D; Innovation & Concentration ratio & Insignificant \\
\hline Scherer (1965) & Patents & Concentration ratio & Insignificant \\
\hline Scott (1984) & R\&D & Concentration ratio & Insignificant \\
\hline
\end{tabular}


Table 3. Summary Statistics: Patents

\begin{tabular}{|l|r|r|r|}
\hline Firm & \multicolumn{1}{|c|}{$\mu^{P A T}$} & \multicolumn{1}{c|}{$\sigma^{P A T}$} & \multicolumn{1}{c|}{$C V^{P A T}(\%)$} \\
\hline GM & 332.7 & 145.8 & 44.3 \\
\hline Ford & 259.8 & 127.5 & 49.1 \\
\hline Chrysler & 78.3 & 61.7 & 78.8 \\
\hline Toyota & 277.0 & 240.3 & 86.8 \\
\hline Honda & 351.0 & 308.2 & 87.8 \\
\hline Nissan & 216.3 & 95.5 & 44.2 \\
\hline VW & 25.2 & 12.7 & 50.4 \\
\hline BMW & 27.5 & 27.8 & 101.1 \\
\hline Daimler & 110.5 & 45.2 & 40.9 \\
\hline Patent (Total) & 1678.3 & 653.3 & 38.9 \\
\hline
\end{tabular}

Notes: $\mu^{P A T}, \sigma^{P A T}$ and $\mathrm{CV}$ are the mean, variance and coefficient of variation (percent) of the total number of patents (for the 9 firms), and for each firm.

Table 4. Summary Statistics: Market Shares and HHI

\begin{tabular}{|l|r|r|r|}
\hline Firm & \multicolumn{1}{|c|}{$\mu^{S H R}$} & \multicolumn{1}{c|}{$\sigma^{S H R}$} & \multicolumn{1}{c|}{$\mathrm{CV}^{S H R}(\%)$} \\
\hline GM & 34.3 & 8.6 & 25.1 \\
\hline Ford & 22.2 & 3.9 & 17.5 \\
\hline Chrysler & 12.6 & 1.8 & 14.3 \\
\hline Toyota & 7.8 & 4.3 & 54.8 \\
\hline Honda & 5.0 & 3.2 & 63.7 \\
\hline Nissan & 4.6 & 1.7 & 36.9 \\
\hline VW & 2.2 & 1.1 & 50.2 \\
\hline BMW & 0.8 & 0.7 & 85.7 \\
\hline Daimler & 1.1 & 0.7 & 67.3 \\
\hline HHI (9 firm) & 2066.4 & 580.9 & 28.1 \\
\hline
\end{tabular}

Notes: $\mu^{S H R}, \sigma^{S H R}$ and CV are the mean, variance and coefficient of variation (percent) of HHI, and the market shares of each firm. HHI is calculated based on the 9 firms in our sample. 
Table 5.1. Own Market Share and HHI (GMM Estimates)

\begin{tabular}{|c|c|c|c|c|}
\hline & 1. All & 2. U.S. & 3. Japanese & 4. German \\
\hline $\ln \left(P A T_{t-1}^{i}\right)$ & $\begin{array}{c}0.746^{* * *} \\
(0.041)\end{array}$ & $\begin{array}{c}0.581^{* * *} \\
(0.051)\end{array}$ & $\begin{array}{c}0.808 * * * \\
(0.043)\end{array}$ & $\begin{array}{c}0.739 * * * \\
(0.060)\end{array}$ \\
\hline $\ln \left(S H R_{t-1}^{i}\right)$ & $\begin{array}{c}0.141^{* *} \\
(0.060)\end{array}$ & $\begin{array}{c}1.048^{* * *} \\
(0.153)\end{array}$ & $\begin{array}{c}0.134 * * * \\
(0.004)\end{array}$ & $\begin{array}{c}0.245^{* * *} \\
(0.080)\end{array}$ \\
\hline $\ln \left(H H I_{t-1}\right)$ & $\begin{array}{c}-0.247 * * * \\
(0.087)\end{array}$ & $\begin{array}{c}-1.008^{* * *} \\
(0.061)\end{array}$ & $\begin{array}{l}-0.083 \\
(0.181)\end{array}$ & $\begin{array}{l}0.064^{*} \\
(0.034)\end{array}$ \\
\hline $\begin{array}{l}\text { Enviro1 (1969-1974) } \\
\text { Environmental }\end{array}$ & $\begin{array}{c}0.111^{* * *} \\
(0.040)\end{array}$ & $\begin{array}{c}0.149 \\
(0.107) \\
\end{array}$ & $\begin{array}{c}0.179 * * \\
(0.076)\end{array}$ & $\begin{array}{c}0.013 \\
(0.165)\end{array}$ \\
\hline $\begin{array}{l}\text { Enviro2 (1989-1994) } \\
\text { Environmental }\end{array}$ & $\begin{array}{l}-0.055 \\
(0.064)\end{array}$ & $\begin{array}{c}0.094 * * \\
(0.043)\end{array}$ & $\begin{array}{c}-0.178^{* * *} \\
(0.055)\end{array}$ & $\begin{array}{l}-0.087 \\
(0.121)\end{array}$ \\
\hline $\begin{array}{l}\text { Bankruptcy } \\
\text { GM }\end{array}$ & $\begin{array}{c}-0.635 * * * \\
(0.055)\end{array}$ & $\begin{array}{c}-0.815 * * * \\
(0.072)\end{array}$ & NA & NA \\
\hline $\begin{array}{l}\text { Merger } \\
\text { Daimler-Chrysler }\end{array}$ & $\begin{array}{c}0.145 * * \\
(0.067)\end{array}$ & $\begin{array}{c}0.242^{* * *} \\
(0.030)\end{array}$ & NA & $\begin{array}{l}-0.044 \\
(0.094)\end{array}$ \\
\hline $\begin{array}{l}\text { VER } \\
\text { Voluntary Export Restraints }\end{array}$ & $\begin{array}{c}-0.028 \\
(0.048)\end{array}$ & $\begin{array}{l}-0.063 \\
(0.110)\end{array}$ & $\begin{array}{l}0.0403 \\
(0.053)\end{array}$ & $\begin{array}{l}-0.080 * \\
(0.047)\end{array}$ \\
\hline$G D P_{t}$ & $\begin{array}{c}0.013^{* *} \\
(0.005)\end{array}$ & $\begin{array}{c}0.012 * * * \\
(0.004)\end{array}$ & $\begin{array}{c}0.011^{* * *} \\
(0.004)\end{array}$ & $\begin{array}{c}0.007 \\
(0.015) \\
\end{array}$ \\
\hline$G D P_{t-1}$ & $\begin{array}{c}0.010 \\
(0.012)\end{array}$ & $\begin{array}{c}0.007 \\
(0.016)\end{array}$ & $\begin{array}{c}-0.007 \\
(0.010)\end{array}$ & $\begin{array}{c}0.021 \\
(0.027)\end{array}$ \\
\hline Observations & 378 & 126 & 126 & 126 \\
\hline Sargan: $\chi^{2}$ (p-value $)$ & $332.59(0.56)$ & $134.81(0.11)$ & $103.93(0.82)$ & $104.50(0.79)$ \\
\hline
\end{tabular}

\section{Notes:}

1. Estimated specification is (see section 3.1):

(5) $\ln \left(P A T_{t}^{i}\right)=\alpha^{i}+\tau_{1} \ln \left(P A T_{t-1}^{i}\right)+\tau_{2} \ln \left(S H R_{t-1}^{i}\right)+\tau_{3} \ln \left(H H I_{t-1}\right)+\vartheta X+\epsilon_{t}^{i}$.

The variables are: $P A T_{t}^{i}-$ Number of patents for firm $i$ in year $\mathrm{t}$; $\alpha^{i}$ - Firm-specific fixed-effect; $S H R_{t-1}^{i}-\mathrm{Market}$ share of firm $i$, lagged one period; $H H_{t-1}-$ Herfindahl index, lagged one period; and vector $\mathbf{X}$ contains the control variables Enviro1, Enviro2, VER, Bankruptcy, Merger, and GDP growth.

2. Estimation is via the Arellano-Bond GMM estimator. Robust standard errors are reported in parentheses, and *, ** and *** denote significance at 1\%, 5\% and 10\% levels. The 'All' sample includes the 9 firms in our sample. The other samples include 3 firms each. The annual data for each firm covers the period 1969-2012. Two initial observations are dropped due to taking lags and the first-differencing procedure of the estimator.

Table 5.2. Own Market Share and HHI (Fixed-Effects IV Estimates)

\begin{tabular}{|c|c|c|c|c|}
\hline & 1. All & 2. U.S. & 3. Japanese & 4. German \\
\hline $\ln \left(P A T_{t-1}^{i}\right)$ & $\begin{array}{c}0.786^{* * *} \\
(0.048)\end{array}$ & $\begin{array}{c}0.427 * * * \\
(0.109)\end{array}$ & $\begin{array}{c}0.892 * * * \\
(0.063)\end{array}$ & $\begin{array}{c}0.784^{* * *} \\
(0.089)\end{array}$ \\
\hline $\ln \left(S H R_{t-1}^{i}\right)$ & $\begin{array}{c}0.126 * * \\
(0.050)\end{array}$ & $\begin{array}{c}1.454^{* * * *} \\
(0.372)\end{array}$ & $\begin{array}{c}0.074 \\
(0.078) \\
\end{array}$ & $\begin{array}{c}0.234^{* *} \\
(0.097)\end{array}$ \\
\hline $\ln \left(H H I_{t-1}\right)$ & $\begin{array}{c}-0.206^{* *} \\
(0.085)\end{array}$ & $\begin{array}{c}-1.310^{* * *} \\
(0.252)\end{array}$ & $\begin{array}{c}-0.015 \\
(0.135)\end{array}$ & $\begin{array}{c}0.101 \\
(0.188)\end{array}$ \\
\hline
\end{tabular}

Notes: See table 5.1 for details. Estimation is via the fixed-effects IV estimator. Only the main variables of interest are reported to save space. Robust standard errors are reported in parentheses, and *, ** and *** denote significance at $1 \%, 5 \%$ and $10 \%$ levels. 
Table 5.3. Estimated Quantitative Effects (actual change): Own Market Share and HHI

\begin{tabular}{|l|c|c|c|c|}
\hline & 1. All & 2. U.S. & 3. Japanese & 4. German \\
\hline$S H R_{t-1}^{i}$ & 30 & 106 & 23 & 10 \\
\hline$H H I_{t-1}$ & -13 & -63 & 0 & 1 \\
\hline$G D P_{t}$ & 2 & 2 & 2 & 0 \\
\hline
\end{tabular}

Notes:

1. Calculations are based on the GMM estimates from table 5.1. Only the main variables of interest are reported to save space.

2. Estimated quantitative effects (as the actual changes in variables) are based on considering a one-standarddeviation change in the relevant independent variable. If the underlying coefficient estimates were insignificant in table 5.1, we assign a value zero to that effect. The estimated quantitative effects are computed as follows. Given the elasticity (significant coefficients in table 5.1), when independent variable $x$ changes from $\bar{x}$ to $(\bar{x}+\sigma)$, the change in value of $P A T_{t}^{i}$ (starting from the initial value: $\overline{P A T_{t}^{l}}$ ).

Table 5.4. Estimated Quantitative Effects (\% change): Own Market Share and HHI

\begin{tabular}{|l|c|c|c|c|}
\hline & 1. All & 2. U.S. & 3. Japanese & 4. German \\
\hline$S H R_{t-1}^{i}$ & $15.86 \%$ & $47.59 \%$ & $8.09 \%$ & $18.62 \%$ \\
\hline$H H I_{t-1}$ & $-6.87 \%$ & $-28.12 \%$ & $0.00 \%$ & $1.79 \%$ \\
\hline$G D P_{t}$ & $0.96 \%$ & $0.89 \%$ & $0.81 \%$ & $0.00 \%$ \\
\hline
\end{tabular}

Notes:

1. Calculations are based on the GMM estimates from table 5.1. Only the main variables of interest are reported to save space. The estimated quantitative effects (as percentage changes) are based on considering a one-standarddeviation change in the relevant independent variable. If the underlying coefficient estimates were insignificant in table 5.1, we assign a value zero to that effect.

Table 5.5. Estimated Elasticities: Own Market Share

\begin{tabular}{|l|c|c|c|c|}
\hline & 1. All & 2. U.S. & 3. Japanese & 4. German \\
\hline Short-run & $0.141^{*}$ & $1.048^{*}$ & $0.134^{*}$ & $0.245^{*}$ \\
\hline Long-run & $0.555^{*}$ & $2.501^{*}$ & $0.698^{*}$ & $0.939^{*}$ \\
\hline
\end{tabular}

Notes:

1. Short-run elasticities are the estimated coefficients for $\ln \left(S H R_{t-1}^{i}\right)$ reported in table 5.1. (As the specification is estimated in log-linear form, the coefficients are interpreted as elasticities.) An asterisk * indicates that the estimate is significant (see table 5.1).

2. Long-run elasticities are calculated as follows: $\left[\frac{\tau_{2}}{\left(1-\tau_{1}\right)}\right]$, where $\tau_{2}$ is the estimated coefficient of $\ln \left(S H R_{t-1}^{i}\right)$ (specification 5.1) and $\tau_{1}$ is the estimated coefficient of the lagged-dependent variable $\ln \left(P A T_{t-1}^{i}\right)$.

Table 5.6. Estimated Elasticities: HHI

\begin{tabular}{|l|c|c|c|c|}
\hline & 1. All & 2. U.S. & 3. Japanese & 4. German \\
\hline Short-run & $-0.247^{*}$ & $-1.008^{*}$ & -0.083 & $0.064^{*}$ \\
\hline Long-run & $-0.972^{*}$ & $-2.406^{*}$ & -0.432 & $0.245^{*}$ \\
\hline
\end{tabular}

Notes:

1. Short-run elasticities are the estimated coefficients for $\ln \left(H H I_{t-1}\right)$ reported in table 5.1. An asterisk * indicates that the estimate is significant (see table 5.1).

2. Long-run elasticities are calculated as follows: $\left[\frac{\tau_{3}}{\left(1-\tau_{1}\right)}\right]$, where $\tau_{3}$ is the estimated coefficient of $\ln \left(H H I_{t-1}\right)$ (specification 5.1) and $\tau_{1}$ is the estimated coefficient of the lagged-dependent variable $\ln \left(P A T_{t-1}^{i}\right)$. 
Table 6.1. Own Market Share and Rivals' Market Shares

\begin{tabular}{|c|c|c|c|c|}
\hline 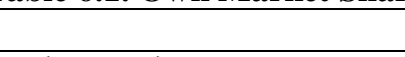 & 1. All & 2. U.S. & 3. Japanese & 4. German \\
\hline $\ln \left(P A T_{t-1}^{i}\right)$ & $\begin{array}{c}0.734 * * * \\
(0.039)\end{array}$ & $\begin{array}{c}0.623 * * * \\
(0.069)\end{array}$ & $\begin{array}{c}0.805^{* * *} \\
(0.031)\end{array}$ & $\begin{array}{c}0.749 * * * \\
(0.075)\end{array}$ \\
\hline $\ln \left(S H R_{t-1}^{i}\right)$ & $\begin{array}{c}0.223^{* * * *} \\
(0.059)\end{array}$ & $\begin{array}{c}0.755^{* * * *} \\
(0.263)\end{array}$ & $\begin{array}{c}0.141^{* * *} \\
(0.022)\end{array}$ & $\begin{array}{c}0.185 \\
(0.126) \\
\end{array}$ \\
\hline $\ln \left(S H R_{t-1}^{\text {Own-Country }}\right)$ & $\begin{array}{l}-0.035 \\
(0.026) \\
\end{array}$ & $\begin{array}{l}-0.365^{*} \\
(0.195) \\
\end{array}$ & $\begin{array}{l}-0.139 \\
(0.146)\end{array}$ & $\begin{array}{l}-0.085 \\
(0.121)\end{array}$ \\
\hline $\ln \left(S H R_{t-1}^{\text {Other-Country:Main }}\right)$ & $\begin{array}{l}0.106^{* *} \\
(0.043)\end{array}$ & $\begin{array}{c}0.274^{* * *} \\
(0.051)\end{array}$ & $\begin{array}{l}-0.218 \\
(0.997)\end{array}$ & $\begin{array}{c}0.168^{* * *} \\
(0.053)\end{array}$ \\
\hline $\ln \left(S H R_{t-1}^{\text {Other-Country:Other }}\right)$ & $\begin{array}{c}0.149 * * * \\
(0.044)\end{array}$ & $\begin{array}{c}0.069 \\
(0.116) \\
\end{array}$ & $\begin{array}{c}0.170 \\
(0.221) \\
\end{array}$ & $\begin{array}{c}0.266 \\
(0.341) \\
\end{array}$ \\
\hline $\begin{array}{l}\text { Enviro1 (1969-1974) } \\
\text { Environmental }\end{array}$ & $\begin{array}{c}0.124 * * * \\
(0.047)\end{array}$ & $\begin{array}{c}0.297 * * * \\
(0.029)\end{array}$ & $\begin{array}{l}-0.047 \\
(0.103)\end{array}$ & $\begin{array}{c}0.180 \\
(0.113)\end{array}$ \\
\hline $\begin{array}{l}\text { Enviro2 (1989-1994) } \\
\text { Environmental }\end{array}$ & $\begin{array}{l}-0.023 \\
(0.077)\end{array}$ & $\begin{array}{c}0.089 \\
(0.080)\end{array}$ & $\begin{array}{l}-0.048 \\
(0.118)\end{array}$ & $\begin{array}{l}-0.191 \\
(0.201)\end{array}$ \\
\hline $\begin{array}{l}\text { Bankruptcy } \\
\text { GM }\end{array}$ & $\begin{array}{c}-0.672^{* * *} \\
(0.061)\end{array}$ & $\begin{array}{c}-0.742 * * * \\
(0.056)\end{array}$ & NA & NA \\
\hline $\begin{array}{l}\text { Merger } \\
\text { Daimler-Chrysler }\end{array}$ & $\begin{array}{l}0.117^{* *} \\
(0.059)\end{array}$ & $\begin{array}{c}0.259 * * * \\
(0.017)\end{array}$ & NA & $\begin{array}{l}-0.043 \\
(0.069) \\
\end{array}$ \\
\hline $\begin{array}{l}\text { VER } \\
\text { Voluntary Export Restraints }\end{array}$ & $\begin{array}{c}-0.082 \\
(0.051) \\
\end{array}$ & $\begin{array}{c}-0.234 * * \\
(0.113) \\
\end{array}$ & $\begin{array}{c}0.053 * * \\
(0.023)\end{array}$ & $\begin{array}{l}-0.103^{*} \\
(0.053) \\
\end{array}$ \\
\hline$G D P_{t}$ & $\begin{array}{l}0.013^{* *} \\
(0.006)\end{array}$ & $\begin{array}{l}0.015^{* *} \\
(0.007)\end{array}$ & $\begin{array}{c}0.017 * * * \\
(0.005)\end{array}$ & $\begin{array}{c}0.002 \\
(0.015)\end{array}$ \\
\hline$G D P_{t-1}$ & $\begin{array}{c}0.009 \\
(0.010)\end{array}$ & $\begin{array}{c}0.005 \\
(0.015) \\
\end{array}$ & $\begin{array}{c}0.003 \\
(0.011)\end{array}$ & $\begin{array}{c}0.014 \\
(0.025) \\
\end{array}$ \\
\hline Observations & 378 & 126 & 126 & 126 \\
\hline Sargan: $\chi^{2}$ ( $p$-value $)$ & 329.17 (0.610) & $131.80(0.122)$ & $102.32(0.814)$ & $101.58(0.810)$ \\
\hline
\end{tabular}

Notes:

1. Estimated specification is (see section 3.2):

(8) $\ln \left(P A T_{t}^{i}\right)=\kappa^{i}+\gamma_{1} \ln \left(P A T_{t-1}^{i}\right)+\gamma_{2} \ln \left(S H R_{t-1}^{i}\right)+\gamma_{3} \ln \left(S_{H} R_{t-1}^{\text {Own-Country }}\right)+\gamma_{4} \ln \left(\right.$ SHR $\left._{t-1}^{\text {Other-Country:Main }}\right)$ $+\gamma_{5} \ln \left(S H R_{t-1}^{\text {Other-Country:Other }}\right)+\xi \boldsymbol{X}+\omega_{t}^{i}$.

The variables are as follows:

$P A T_{t}^{i}$ : Number of patents for firm $i$ in year $\mathrm{t}$.

$\kappa^{i}$ : Firm-specific fixed-effect.

$S H R_{t-1}^{i}$ : Market share of firm $i$, lagged one period.

$S H R_{t-1}^{\text {Own-Country }}$ : Market share of own-country rivals of firm $i$, lagged one period.

$S H R_{t-1}^{\text {Other-Country:Main }}$ : Market share of other-country 'main' rivals of firm $i$, lagged one period.

$S H R_{t-1}^{\text {Other-Country:Other }}$ : Market share of other-country 'other' rivals of firm $i$, lagged one period.

Vector $\mathbf{X}$ contains: Enviro1, Enviro2, VER, Bankruptcy, Merger, and GDP growth.

2. Estimation is via the Arellano-Bond GMM estimator. Robust standard errors are reported in parentheses, and *, ** and *** denote significance at $1 \%, 5 \%$ and $10 \%$ levels. The 'All' sample includes the 9 firms in our sample. The other samples include 3 firms each. The annual data for each firm cover the period 1969-2012. Two initial observations are dropped due to taking lags and the first-differencing procedure of the estimator. 
Table 6.2. Estimated Quantitative Effects (actual change): Own and Rivals’ Market Shares

\begin{tabular}{|l|c|c|c|c|}
\hline & 1. All & 2. U.S. & 3. Japanese & 4. German \\
\hline$S H R_{t-1}^{i}$ & 47 & 77 & 24 & 0 \\
\hline$S H R_{t-1}^{\text {Own-Country }}$ & 0 & -22 & 0 & 0 \\
\hline$S H R_{t-1}^{\text {Other-Country:Main }}$ & 15 & 31 & 0 & 5 \\
\hline$S H R_{t-1}^{\text {Other-Country:Other }}$ & 34 & 0 & 0 & 0 \\
\hline$G D P_{t}$ & 2 & 2 & 4 & 0 \\
\hline
\end{tabular}

Notes:

1. Calculations are based on the GMM estimates from table 6.1. Only the main variables of interest are reported to save space.

2. Estimated quantitative effects (as actual changes in variables) are based on considering a one-standard-deviation change in the relevant independent variable. If the underlying coefficient estimates were insignificant in table 8, we assign a value zero to that effect. The estimated quantitative effects are computed as follows. Given the elasticity (significant coefficients in table 6.1), when independent variable $x$ changes from $\bar{x}$ to $(\bar{x}+\sigma)$, the change in value of $P A T_{t}^{i}$ (starting from the initial value: $\overline{P A T_{t}^{l}}$ ).

Table 6.3. Estimated Quantitative Effects (\% change): Own and Rivals’ Market Shares

\begin{tabular}{|l|c|c|c|c|}
\hline & 1. All & 2. U.S. & 3. Japanese & 4. German \\
\hline$S H R_{t-1}^{i}$ & $25.09 \%$ & $34.29 \%$ & $8.52 \%$ & $0.00 \%$ \\
\hline$S H R_{t-1}^{\text {Own-Country }}$ & $0.00 \%$ & $-9.97 \%$ & $0.00 \%$ & $0.00 \%$ \\
\hline$S H R_{t-1}^{\text {Other-Country:Main }}$ & $8.08 \%$ & $13.94 \%$ & $0.00 \%$ & $8.55 \%$ \\
\hline$S H R_{t-1}^{\text {Other-Country:Other }}$ & $18.20 \%$ & $0.00 \%$ & $0.00 \%$ & $0.00 \%$ \\
\hline$G D P_{t}$ & $0.96 \%$ & $1.11 \%$ & $1.26 \%$ & $0.00 \%$ \\
\hline
\end{tabular}

Notes:

1. Calculations are based on the GMM estimates from table 6.1. Only the main variables of interest are reported to save space.

2. Estimated quantitative effects are based on considering a one-standard-deviation change in the relevant independent variable. If the underlying coefficient estimates were insignificant in table 8 , we assign a value zero to that effect. 